\title{
Social Stimuli Induce Activation of Oxytocin Neurons Within the Paraventricular Nucleus of the Hypothalamus to Promote Social Behavior in Male Mice
}

\author{
Shanna L. Resendez, ${ }^{1}$ Vijay Mohan K. Namboodiri, ${ }^{1,2}$ James M. Otis, ${ }^{1,2}$ Louisa E.H. Eckman, ${ }^{1}$ \\ Jose Rodriguez-Romaguera, ${ }^{1,2,3}$ Randall L. Ung, ${ }^{2,3}$ ๑Marcus L. Basiri, ${ }^{2,3}$ Oksana Kosyk, ${ }^{1}$ Mark A. Rossi, ${ }^{1,2}$ \\ Gabriel S. Dichter, ${ }^{1,3,4}$ and $\mathbb{C}$ Garret D. Stuber ${ }^{1,3}$ \\ ${ }^{1}$ Departments of Psychiatry and Cell Biology and Physiology, ${ }^{2}$ Neuroscience Center, ${ }^{3}$ Curriculum in Neuroscience, and ${ }^{4}$ Carolina Institute for \\ Developmental Disabilities, University of North Carolina at Chapel Hill, Chapel Hill, North Carolina 27516
}

Oxytocin (OT) is critical for the expression of social behavior across a wide array of species; however, the role of this system in the encoding of socially relevant information is not well understood. In the present study, we show that chemogenetic activation of OT neurons within the paraventricular nucleus of the hypothalamus (PVH) of male mice (OT-Ires-Cre) enhanced social investigation during a social choice test, while chemogenetic inhibition of these neurons abolished typical social preferences. These data suggest that activation of the OT system is necessary to direct behavior preferentially toward social stimuli. To determine whether the presence of a social stimulus is sufficient to induce activation of PVH-OT neurons, we performed the first definitive recording of OT neurons in awake mice using two-photon calcium imaging. These recordings demonstrate that social stimuli activate PVH-OT neurons and that these neurons differentially encode social and nonsocial stimuli, suggesting that PVH-OT neurons may act to convey social salience of environmental stimuli. Finally, an attenuation of social salience is associated with social disorders, such as autism. We therefore also examined possible OT system dysfunction in a mouse model of autism, Shank $3 b$ knock-out (KO) mice. Male Shank $3 b$ KO mice showed a marked reduction in PVH-OT neuron number and administration of an OT receptor agonist improved social deficits. Overall, these data suggest that the presence of a social stimulus induces activation of the PVH-OT neurons to promote adaptive social behavior responses.

Key words: 2-photon; autism; calcium imaging; DREADDs; hypothalamus; oxytocin

Significance Statement

Although the oxytocin (OT) system is well known to regulate a diverse array of social behaviors, the mechanism in which $0 \mathrm{~T}$ acts to promote the appropriate social response is poorly understood. One hypothesis is that the presence of social conspecifics activates the OT system to generate an adaptive social response. Here, we selectively recorded from OT neurons in the paraventricular hypothalamic nucleus (PVH) to show that social stimulus exposure indeed induces activation of the $0 \mathrm{~T}$ system. We also show that activation of the OT system is necessary to promote social behavior and that mice with abnormal social behavior have reduced numbers of PVH-OT neurons. Finally, aberrant social behavior in these mice was rescued by administration of an OT receptor agonist.

\section{Introduction}

The capacity to detect and interpret social cues is fundamental to the expression of adaptive social behaviors that are critical for

Received June 14, 2018; revised Jan. 20, 2020; accepted Jan. 23, 2020.

Author contributions: S.L.R., G.S.D., and G.D.S. designed research;S.L.R., V.M.K.N., J.M.O., J.R.-R., R.L.U., M.L.R., and G.D.S. analyzed data; S.L.R., V.M.K.N., J.M.O., R.L.U., M.L.B., G.S.D., and G.D.S. edited the paper; S.L.R. and G.D.S. wrote the paper; J.M.O., L.E.H.E., J.R.-R., M.L.B., O.K., and M.A.R. performed research; M.L.B. contributed unpublished reagents/analytic tools.

This work was supported by the Simon's Foundation and the National Institute for Child Health and Human Development (NICHD) (HD079124), Yang Family Biomedical Scholars Award and the National Institute on Drug Abuse (DA032750 and DA038168). S.L.R. was supported by NICHD T32 Grant (HD040127). We thank Ben Philpot, species survival (Bachner-Melman and Ebstein, 2014). Specifically, an individual must be able to identify a social stimulus

Joseph Piven, Sheryl Moy, and the members of the Stuber laboratory for helpful discussions; the UNC vector core for viral packaging; Bradford B. Lowell for the oxytocin-Ires-Cre mice; and the UNC center microscopy core (P30 NS045892).

The authors declare no competing financial interests.

Correspondence should be addressed to Garret D. Stuber at gstuber@uw.edu.

G.S.D. Stuber's present address: Center for the Neurobiology of Addiction, Pain, and Emotion, Departments of Anesthesiology and Pain Medicine, and Pharmacology, University of Washington, Seattle, WA 98195.

https://doi.org/10.1523/JNEUROSCI.1515-18.2020

Copyright $\odot 2020$ the authors 
within a complex environment, evaluate the properties of this stimulus, and select the proper behavioral response (Silverman et al., 2010). Thus, the first step to the successful expression of social behavior is the encoding of stimuli as social. Without this fundamental first step, more complex social behavioral processes that are necessary for species survival, such as mating and defensive behavior, cannot occur. Importantly, although the encoding of social information is critical for species survival, the neural mechanisms that enable the conveyance of social salience are not well understood.

Oxytocin (OT) is a neuropeptide that plays a broad role in modulating the social repertoire of species across the animal kingdom (Insel, 1992; Donaldson and Young, 2008; Neumann, 2008; Bales and Perkeybile, 2012; Carter, 2014; Tabbaa et al., 2016). To date, the OT system has been associated with social recognition (Oettl et al., 2016), social learning and memory (Ferguson et al., 2001; Choe et al., 2015), social reward (Dölen et al., 2013; Young et al., 2014), attachment formation (Insel, 1992; Wang and Aragona, 2004; Young and Wang, 2004), sexual behavior (Bitran and Hull, 1987; Yanagimoto et al., 1996; Caquineau et al., 2006; Ludwig and Leng, 2006), parental care (Pedersen and Prange, 1979; Bell et al., 2014; Marlin et al., 2015; Scott et al., 2015; Bales and Saltzman, 2016; Mitre et al., 2016), and aggression (Ebner et al., 2000; Anacker et al., 2016; Ne'eman et al., 2016; Zimmermann et al., 2016). The pervasive influence of the OT system extends to social contexts of both positive and negative valence and may play a critical role in the regulation of processes that are fundamental to the expression of all social behaviors (Choe et al., 2015; Nardou et al., 2019). More specifically, it is hypothesized that the presence of a social conspecific activates the OT system to produce a heightened OT tone that in turn acts to promote the onset and maintenance of social interactions (Neumann, 2007; Oettl et al., 2016), in part through enhancing the salience of social stimuli (Bartz et al., 2011). However, it has yet to be determined how the presence of a social conspecific modulates the activity of OT neurons within the PVH.

In the present study, we performed recordings of OT neurons in awake mice by using a genetically encoded calcium indicator (GECI; GCaMP6s) (Chen et al., 2013) in combination with 2-photon calcium imaging through a gradient refractive index (GRIN) lens to selectively monitor the activity of PVH-OT neurons. These data reveal that conspecific animal presentation increases the activity of OT neurons and that OT neurons were more robustly activated in response to socially rewarding stimuli compared with a nonsocial, appetitive stimulus. In addition, chemogenetic modulation (Alexander et al., 2009) of PVH-OT neurons revealed that activation of these neurons is required for the proper expression of social behavior. Finally, impairments in social attention have been considered to be one of the core deficits in autism spectrum disorders (ASD) (Chevallier et al., 2012) and in the present study we identified that a mouse model of ASD (Shank3b KO mice) has reduced numbers of PVH-OT neurons. Importantly, well characterized deficits in the social behavior of Shank3b KO mice (Peça et al., 2011) were rescued by i.p. administration of an OT receptor agonist suggesting that aberrant activity in the OT system may contribute to core deficits in social behavior associated with ASD. In total, these data support the hypothesized mechanism that upon detection of a social stimulus, OT neurons become activated to promote engagement with social conspecifics. These data also provide support for the therapeutic potential of OT in the treatment of social pathologies associated with deficits in social attention and may be valuable in informing targeted interventions for the treatment of social disorders.

\section{Materials and Methods}

Experimental subjects. Adult male heterozygous and homozygous OTIres-Cre (Wu et al., 2012) mice were used as test subjects for experiments requiring direct interrogation of the OT system. Shank $3 b \mathrm{KO}$ mice (heterozygous and homozygous) (Peça et al., 2011) (The Jackson Laboratory) as well as wild-type littermates were used to determine whether deficits in the OT system contribute to ASD-like symptoms. Juvenile (3-5 weeks old) male CD-1 mice were used as stimulus animals (The Jackson Laboratory). All procedures were conducted in accordance with the guides for animal care and use as outlined in the Guide for the Care and Use of Laboratory Animals (NIH) and Institutional Care and Use Committee at the University of North Carolina (UNC) at Chapel Hill.

Virus constructs and stereotactic surgery. Cre-inducible hM3DqmCherry (AAV8-hsyn-DIO-hM3D(Gq)-mCherry), hM4Di-mCherry (AAV8-hsyn-DIO-hM4D(Gi)-mCherry), and GCaMP6s (AAVdj-EF1 $\alpha$ DIO-GCaMP6s) were all packaged at the UNC Viral Vector Core Facility. All viruses were stored in $5 \mu \mathrm{l}$ aliquots at $-80^{\circ} \mathrm{C}$ until the day of use. Before surgery, mice were anesthetized with $1.0-1.5 \%$ isoflurane mixed with pure oxygen $(1 \mathrm{~L} / \mathrm{min}$ ) and fixed in a stereotactic apparatus (David Kopf Instruments). Once the subject was secure in the apparatus, the surgery area was scrubbed with alternating washes of povidine-iodine (Butler Schein) and alcohol (Fisher), ophthalmic ointment (Akorn) was applied to the eye, and topical Lidocaine (2\%, Akorn) was applied to the scalp. For chemogenetic experiments, virus injections $(500 \mathrm{~nL} / \mathrm{min})$ were administered bilaterally to the PVH (AP $-0.8, \mathrm{ML}+/-0.3$, DV -4.75 ). For calcium imaging experiments, two injections $(500 \mathrm{~nL} / \mathrm{min})$ were made on either side of the planned lens placement (AP - 0.8, ML 0.1 and 0.55 , DV -4.8). After sufficient time was allowed for the virus to diffuse, a $0.6 \mathrm{~mm}$ diameter, $7.3 \mathrm{~mm}$ length GRIN lens (Inscopix) was implanted above the PVH. The lens was lowered at a constant, slow rate $(100 \mu \mathrm{m} /$ $\mathrm{min}$ ) to its final position above the PVH (AP - 0.8, ML 0.20, DV - 4.65). A custom head ring was then placed around the lens to allow for head fixation during the 2-photon imaging procedure. The lens and head ring were secured into place with skull screws, Metabond (Parkell), and dental cement (Lang Dental). Following the surgery, subjects were administered acetaminophen for $3 \mathrm{~d}(80 \mathrm{mg} / 200 \mathrm{ml}$ of water).

Behavioral assays. For chemogenetic experiments, animals were tested in a 3 -chamber social choice task ( $10 \mathrm{~min}$ baseline and $10 \mathrm{~min}$ test). They received either an i.p. injection of clozapine- $\mathrm{N}$-Oxide $(\mathrm{CNO} ; 1 \mathrm{mg} / \mathrm{kg}$ ) or saline $45 \mathrm{~min}$ before behavioral testing with at least $4 \mathrm{~d}$ in between experiments. All behavioral sessions were counterbalanced (Crawley, 2008; Silverman et al., 2010). For behavioral pharmacology experiments, test subjects received i.p. injections of the OT receptor agonist, Way267464 (10 or $30 \mathrm{mg} / \mathrm{kg}$ ) (Tocris Biosciences) dissolved in 15\% dimethylsulphoxide (DMSO) and 2\% Tween, or vehicle (saline, DMSO, and Tween) 30 min before the 3-chamber social choice test (Ring et al., 2010; Hicks et al., 2012; Olszewski et al., 2014). These doses and time points were chosen based on previous studies demonstrating behavioral effects in mice (Ring et al., 2010; Olszewski et al., 2014). Automated animal-tracking software was used to determine the distance from social stimuli (Ethovision, Noldus Technologies). Specifically, three-point video tracking was used to track the nose of the test subject and a zone only large enough for the test subjects head to fit was created to estimate sniff duration. Thus, duration in zone is determined only by the duration of time the test subject nose was spent in close proximity to the social stimulus. For head-fixed behavioral experiments, test subjects were habituated to the head-fixation apparatus and stimulus exposure for 5 sessions before testing. On the test day, subjects were exposed to either a novel social stimulus (anesthetized male juvenile) or a nonsocial object (empty plastic bottle) for 5 min by directly placing the stimulus in front of the test subject. Each stimulus was placed approximately an inch away from the test subject subjects face. Test subjects also underwent two sessions of random-sucrose delivery (100 trials/session) where sucrose was delivered at random intervals through a lick spout placed directly in front of the subject (Otis et al., 2017) to determine whether responses of PVH-OT neurons were specific 
to socially rewarding stimuli or general to other types of rewards, such as palatable food.

Head-fixed 2-photon calcium imaging. PVH-OT neurons were imaged through a chronically implanted GRIN lens positioned above the PVH (Resendez et al., 2016) using 2-photon microscopy. Imaging data from PVH-OT neurons expressing GCaMP6s (AAVdj-EF1 $\alpha$-DIO-GCaMP6s) were acquired with an Olympus 2-photon microscope (FVMPE-RS) using a resonant scanner with 6 frame online averaging, resulting in an effective frame rate of $5 \mathrm{~Hz}$. The microscope was equipped with gallium arsenide phosphide photomultiplier tubes (GaAsP-PMTs) with adjustable voltage, gain, and offset features, a single green/red NDD filter cube, a long working distance $20 \times$ air objective designed for optical transmission at infrared wavelengths (Olympus, LCPLN20XIR, 0.45 NA, $8.3 \mathrm{~mm}$ WD), a software-controlled XY stage loaded on a manual $z$-deck, and a tunable Mai-Tai Deep See EPS laser system (Spectra Physics, laser set to $955 \mathrm{~nm}, \sim 100 \mathrm{fs}$ pulse width) with automated four-axis alignment. At the start of each imaging session, a field of view (FOV) was selected by adjusting the $z$-axis of the imaging plane to identify the plane that contained the highest number of PVH-OT neurons. A computer equipped with FluoView (Olympus, FV1200) and cellSens (Olympus) was used to acquire and process imaging data. Acquired videos were motion corrected using a planar hidden Markov model using the SIMA software package (Kaifosh et al., 2014) and then a SD image across the entire session was generated from the motion corrected image series and used for region of interest (ROI) analysis. ROIs, corresponding to somata of OT neurons, were hand drawn around each cell in ImageJ and SIMA was used to extract calcium transient time series data.

Calcium events were detected as previously described (McHenry et al., 2017). Briefly, for each ROI, extracted fluorescence intensity time series data were independently $z$-scored and then smoothed with a 3-frame rolling mean. Calcium transients were classified as events if the transient magnitude exceeded 1 SD for at least $500 \mathrm{~ms}$. The start and end of each event were defined as the points at which the normalized signal crossed the 1 SD threshold, and the duration of each event was calculated using these boundaries. The peak amplitude was the maximum normalized intensity value within each event. For the rare instances in which acquisition started or ended during an ongoing calcium event, that event was removed from all subsequent analyses. To account for basal differences in calcium dynamics, event rate, duration, and amplitude from each experimental epoch (prestimulus baseline, stimulus, and poststimulus) were normalized by the within-condition (social or nonsocial stimulus) prestimulus mean.

To classify neurons by their response to the social or nonsocial stimulus, neurons were sorted by their median response to each stimulus and classified as either no response $(p>0.05)$, positive response (median response greater than zero, $p<0.05$ ), or negative response (median response less than zero, $p<0.05$ ). Median response to a stimulus was defined as the median fluorescence during the stimulus presentation minus the median fluorescence during the baseline before the stimulus presentation. The median response was used in this case as a robust central tendency measure instead of a mean as the epochs were $5 \mathrm{~min}$ each. For sucrose responses, the same approach was used, but with a mean used as the central tendency measure instead of median, as the epochs for stimulus and baseline in this case were much shorter $(2 \mathrm{~s}$ before the first lick after sucrose delivery for baseline and $2 \mathrm{~s}$ after this first lick for signal). A Wilcoxon signed-rank test was performed to determine significance for each neuron. The $\mathrm{p}$ values were corrected for multiple comparisons across neurons using the Benjamini-Hochberg false discovery rate correction. In addition, previous in vivo recordings from putative PVH-OT neurons have indicated that these neurons display a heterogeneous pattern of firing activity (Poulain and Wakerley, 1982). Baseline spontaneous calcium activity was used to classify cells as either highly fluctuating or low fluctuating. This was done by calculating the mean power of each cell across all the frequencies until the Nyquist frequency. The power at each frequency was calculated using a fast Fourier transform of the signal using Numpy and taking the mean squared of the absolute value. Downstream analysis of all extracted data was performed using custom code written in Python and available at https:// github.com/stuberlab/resendez-et-al-2018.
Patch-clamp electrophysiology. Mice expressing GCaMP in OT neurons were anesthetized with pentobarbital $(50 \mathrm{mg} / \mathrm{kg})$ before transcardial perfusion with ice-cold sucrose cutting solution $\left(0-2^{\circ} \mathrm{C} ; 305 \mathrm{mOsm}\right)$ containing the following (in mM): 225 sucrose, $119 \mathrm{NaCl}, 1.0 \mathrm{NaH}_{2} \mathrm{PO}_{4}, 4.9$ $\mathrm{MgCl}_{2}, 0.1 \mathrm{CaCl}_{2}, 26.2 \mathrm{NaHCO}_{3}, 1.25$ glucose. Brains were then rapidly removed, and horizontal sections $300 \mu \mathrm{m}$ thick were taken using a vibratome (Leica, VT 1200). Sections were then incubated in aCSF $\left(32^{\circ} \mathrm{C}\right.$; $\sim 306 \mathrm{mOsm}$ ) containing the following (in $\mathrm{mm}$ ): $119 \mathrm{NaCl}, 2.5 \mathrm{KCl}, 1.0$ $\mathrm{NaH}_{2} \mathrm{PO}_{4}, 1.3 \mathrm{MgCl}, 2.4 \mathrm{CaCl}_{2}, 26.2 \mathrm{NaHCO}_{3}, 15$ glucose. After an hour of recovery, slices were constantly perfused with aCSF and visualized using differential interference contrast through a $40 \times$ water-immersion objective mounted on an upright microscope (Olympus BX51WI). Whole-cell recordings were obtained using borosilicate patch pipettes (3-5 M $\Omega$ ) back-filled with internal solution ( $\mathrm{pH} 7.35 ; 270-285 \mathrm{mOsm}$ ) containing the following (in mM): $130 \mathrm{~K}$ gluconate, $10 \mathrm{KCl}, 10 \mathrm{HEPES}, 10$ EGTA, $2 \mathrm{MgCl}_{2}$, 2 ATP, 0.2 GTP.

Current-clamp recordings were obtained from PVH GCaMP6sexpressing neurons to characterize how evoked action potential firing correlated with GCaMP6s fluorescence. Specifically, to determine how elevations in action potential frequency changed GCaMP6s fluorescence, a $1 \mathrm{~s}$ train of depolarizing pulses ( $2 \mathrm{nA}, 2 \mathrm{~ms}$ ) was applied at 1,2, 5, 10, or $20 \mathrm{~Hz}$. Electrophysiological data were acquired at $10 \mathrm{kHz}$ sampling rate through a MultiClamp 700B amplifier connected to a Digidata 1440A digitizer (Molecular Devices). Data were analyzed using Clampfit 10.3 (Molecular Devices). During recordings, GCaMP6s fluorescence dynamics were visualized using a LED $(490 \mathrm{~nm},<1$ $\mathrm{mW}$ ) integrated into the light path (ThorLabs: catalog \#LED4c4-SP; LED driver catalog \#LEDD1B) and a microscope-mounted camera (QImaging, optiMOS). Imaging data were acquired using MicroManager and extracted through hand-drawn regions of interest for each recorded neuron using ImageJ.

Immunofluorescence detection and quantification of oxytocin. Mice were anesthetized with pentobarbital $(50 \mathrm{mg} / \mathrm{kg})$ and transcardially perfused with cold $0.01 \mathrm{M}$ PBS, followed by $4 \%$ paraformaldehyde (PFA) in PBS. Tissue was postfixed for $24 \mathrm{~h}$ in $4 \%$ PFA and cryoprotected in $30 \%$ sucrose/PBS before collecting $40 \mu \mathrm{m}$ coronal brain sections. All following steps were performed with gentle shaking. Sections were permeabilized for $10 \mathrm{~min}$ in $0.1 \%$ Triton X-100 (Sigma-Aldrich, T8787) in PBS (PBST) at room temperature, followed by 25 min washes in PBS. Sections were then washed for $30 \mathrm{~min}$ in $0.5 \%$ PBST, followed by PBS for 10 min. Tissue was then blocked for $1 \mathrm{~h}$ in 1:10 donkey serum:0.01\% PBST and incubated for $48 \mathrm{~h}$ at $4^{\circ} \mathrm{C}$ in primary antibody (1:2500 rabbit antioxytocin, Peninsula Laboratories, T-4084, lot \#A13094) added to the previous wells. Sections were washed 4 times for $10 \mathrm{~min}$ in PBS before incubation in secondary antibody (1:200 donkey anti-rabbit 405, Jackson ImmunoResearch, 711-475-152) in PBS for $2 \mathrm{~h}$ at room temperature. Finally, sections were washed 4 times in PBS for $10 \mathrm{~min}$, mounted with 4'6 diamidion-2-phenylindole (DAPI), and coverslipped. The number of cells that stained positive for OT were counted using ImageJ cell counter. Cells were counted in the rostral $(-0.50$ to -0.65 bregma), medial ( -0.70 to -0.85 bregma), and caudal ( -0.9 to -1.1 bregma) PVN of Shank3b KO mice (heterozygous and homozygous) as well as their wildtype littermates. There were $4-5$ mice per group and 1-3 sections analyzed per subject.

Statistical analysis. Statistical significance was assessed with either a $t$ test or two-way ANOVA when applicable. The $\alpha$ level was set to 0.05 for all statistical analysis. All analyses were performed using GraphPad Software (version 7.0a) or custom analysis scripts written in Python.

\section{Results \\ PVH-OT neurons bidirectionally modulate socially motivated behavior}

To determine the social behavioral consequences of PVH-OT neuron modulation, Cre-dependent Gq- or Gi-coupled excitatory DREADD was bilaterally injected into the PVH of OT-IresCre (OT-Cre) mice, resulting in the expression of either $\mathrm{hM} 4 \mathrm{D}(\mathrm{Gq})$ or hM4D(Gi) in PVH-OT neurons. Cloazapine- $N$ Oxide $(\mathrm{CNO})$ was administered $45 \mathrm{~min}$ before social choice test- 
A Cre-inducible Gq- or Gi -DREADD

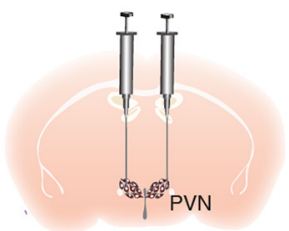

D

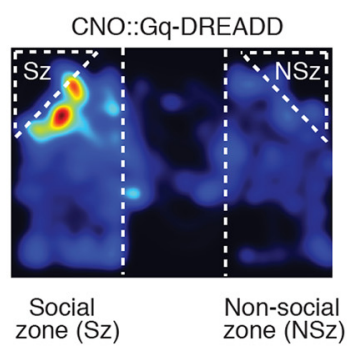

G
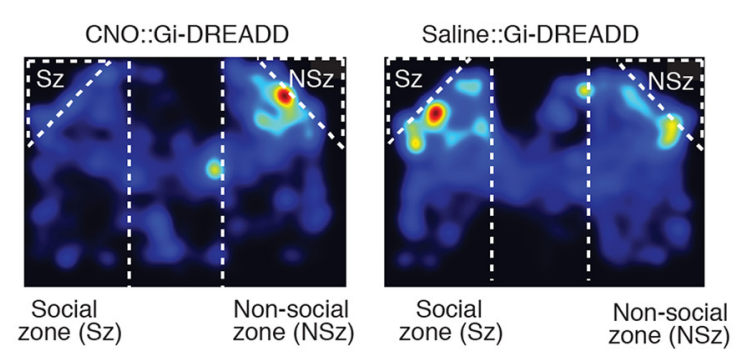

H

E

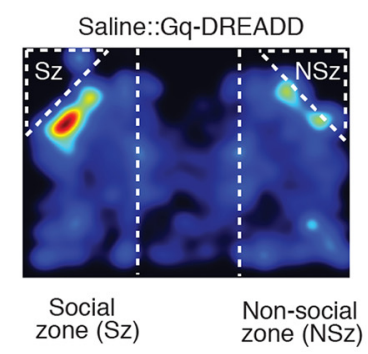

Inject with CNO or saline
$45-$ min before testing

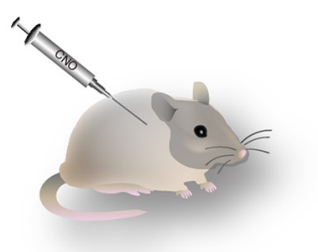

zone $(\mathrm{Sz})$
C

Social choice test (10 $\mathrm{min})$

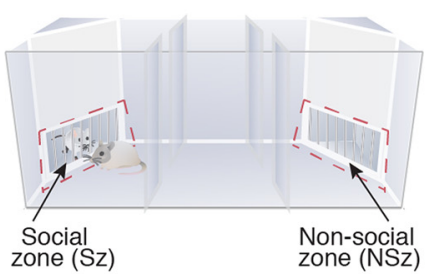

$\mathbf{F}$

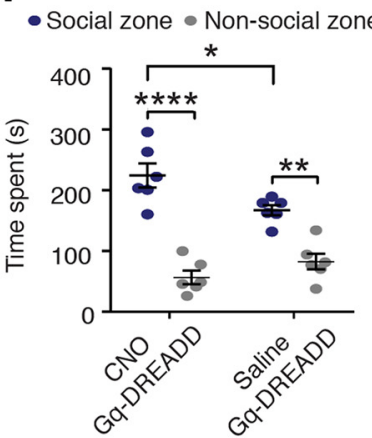

|

- Social zone - Non-social zone

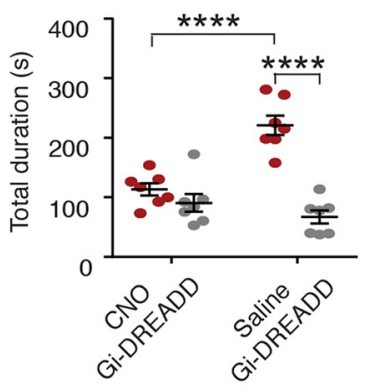

L.Social zone • Non-Social zone

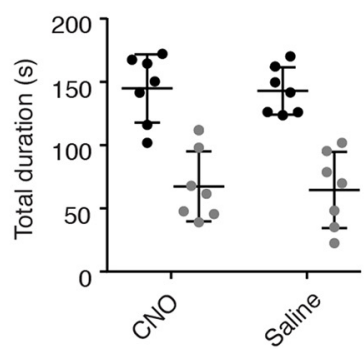

Figure 1. Activation of PVH-OT neurons facilitates social behavior and promotes social orienting. $A-C$, Diagram of experimental design. $\boldsymbol{D}, \boldsymbol{E}$, Representative activity heat maps from $\mathrm{PVH}^{\mathrm{OT}}$.:Gq-DREADD mice injected with either $(\boldsymbol{D})$ CNO or $(\boldsymbol{E})$ saline. $\boldsymbol{F}$, $\mathrm{PVH}^{0 \mathrm{O}}:$ :Gq-DREADD mice administered either $\mathrm{CNO}$ or saline displayed a preference for social stimulus investigation. However, chemogenetic activation of PVH-OT neurons increased time spent investigating the social stimulus $(n=6) . \mathbf{G}, \boldsymbol{H}$, Representative activity heat maps from PVH ${ }^{0 T}:$ :Gi-DREADD mice injected with either $(\mathbf{G})$ CNO or $(\boldsymbol{H})$ saline. I, Gi-DREADD mediated inhibition of PVH-OT neurons impairs preferences for social stimulus investigation and attenuates the total duration of time spent investigating a social stimulus ( $n=7 /$ group). J, $\boldsymbol{K}$, Representative activity heat maps from Cre-negative mice injected with either $(\boldsymbol{J})$ CNO or $(\boldsymbol{K})$ saline. $L$, For Cre-negative littermates, CNO did not alter time spent in the social or nonsocial zone when compared with saline controls $(n=7) .{ }^{*} p \leq 0.05,{ }^{* *} p \leq 0.005,{ }^{* * *} p \leq 0.00005$.

ing to either activate or inhibit PVH-OT neurons (Fig. $1 A-C$ ). During the social choice test, mice could freely investigate a chamber containing either a juvenile stimulus (social zone) or an empty chamber (control; nonsocial zone) (Fig. 1C).

Mice typically prefer to spend more time investigating the social zone compared with the nonsocial zone (Silverman et al.,
2010). Indeed, for mice expressing GqDREADD in PVH-OT neurons, both saline and $\mathrm{CNO}$ injections resulted in a greater duration of time investigating the social stimulus compared with the nonsocial zone (two-way ANOVA, $F_{(1,20)}=$ 85.44, $p<0.0001$; Tukey's post hoc test, CNO: $p<0.0001$, saline: $p=0.002, n=$ $6)$, indicating that both groups of mice showed typical patterns of mouse social behavior (Fig. 1D-F). However, compared with saline injections, $\mathrm{CNO}$ administration resulted in a greater duration of time to be spent investigating the social zone (Tukey's post hoc test, $p=0.04, n=$ 6 ), suggesting that chemogenetic Gq modulation of PVH-OT neurons can enhance normal levels of sociability in mice.

We next determined whether activation of PVH-OT neurons is required for the normal expression of mouse social behavior by chemogenetically inhibiting PVH-OT neurons during the social choice test. Chemogenetic inhibition of PVH-OT neurons significantly impaired typical social behavioral responses in mice (two-way ANOVA, $F_{(1,24)}=43.57, p<$ $0.0001, n=7$ ) (Fig. $1 G-I$ ). Specifically, Gi-DREADD mediated inhibition of PVH-OT neurons resulted in a loss of preference for social stimulus investigation (Tukey's post hoc test, $p=0.63, n=$ $7)$. In contrast, saline administration before the social choice test resulted in robust preferences for social stimulus investigation (Tukey's post hoc test, $p<$ $0.0001, n=7)$. In addition, when subjects were administered saline they spent a significantly higher level of time in the social zone compared with test sessions when CNO was administered (Tukey's post hoc test, $p<0.0001, n=7$ ) (Fig. 1I). Together, these results suggest that endogenous activity of PVH-OT neurons is required to direct investigatory behaviors toward stimuli of social significance. Moreover, control mice (i.e., cre-negative litter mates) that received injections of CNO did not show a difference in social behavior compared with mice that received injections of saline $\left(F_{(1,24)}=1.72\right.$, $p=0.96, n=7$ ) (Fig. $1 \mathrm{~J}, L)$. These data indicate that the effects on social behavior were a direct result of chemogenetic modulation of PVH-OT neurons and not a result of potential nonspecific effects of CNO. In addition, compared with saline, $\mathrm{CNO}$ did not significantly alter the duration of time spent in the nonstimulus zones of the test chamber (i.e., the social chamber, the center chamber, or the nonsocial chamber) (Gq-DREADD: twoway ANOVA, $F_{(1,30)}=0.45, p=0.83$; Gi-DREADD, two-way ANOVA, Gi-DREADD: two-way ANOVA, $F_{(1,36)}=0.22, p=0.65$ ) indicating the effect of $\mathrm{CNO}$ was directly on social stimulus investi- 
A
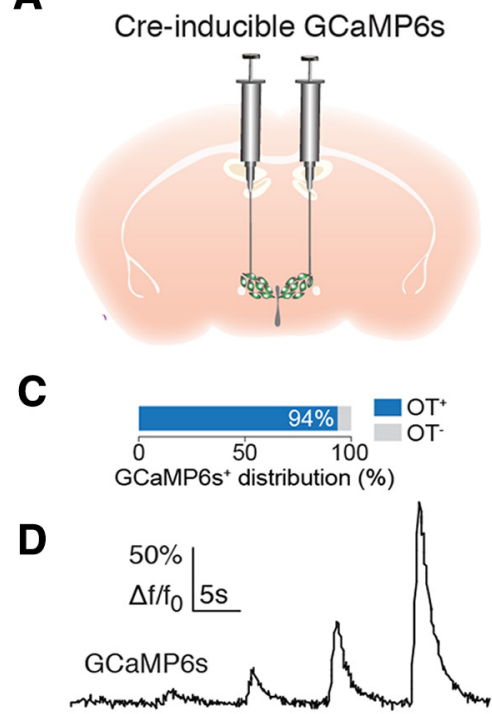

Electrophysiology

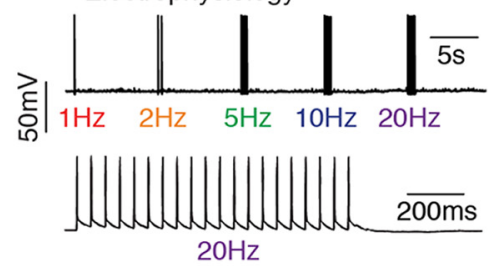

B

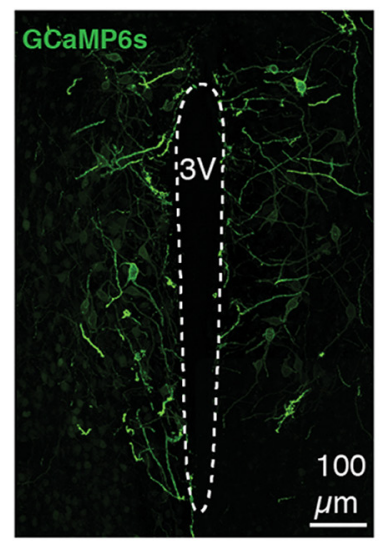

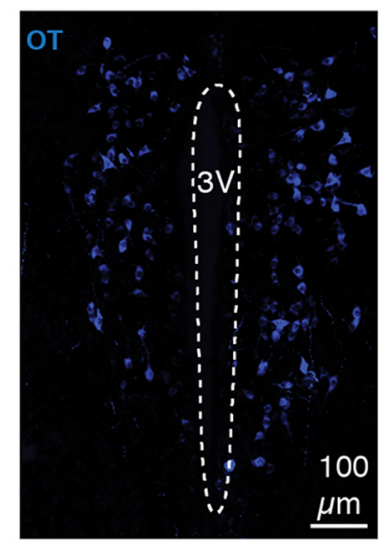

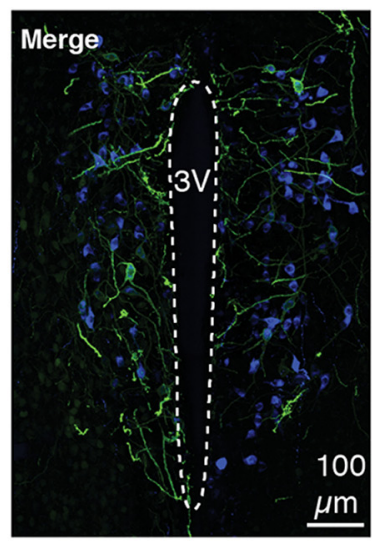

E

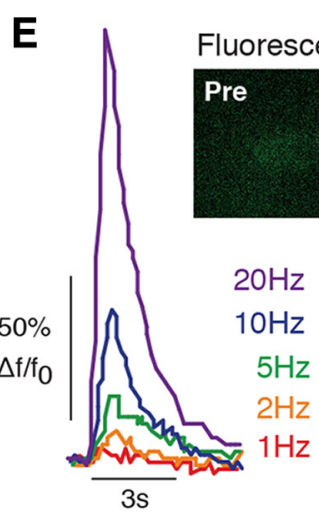

Fluorescent peaks
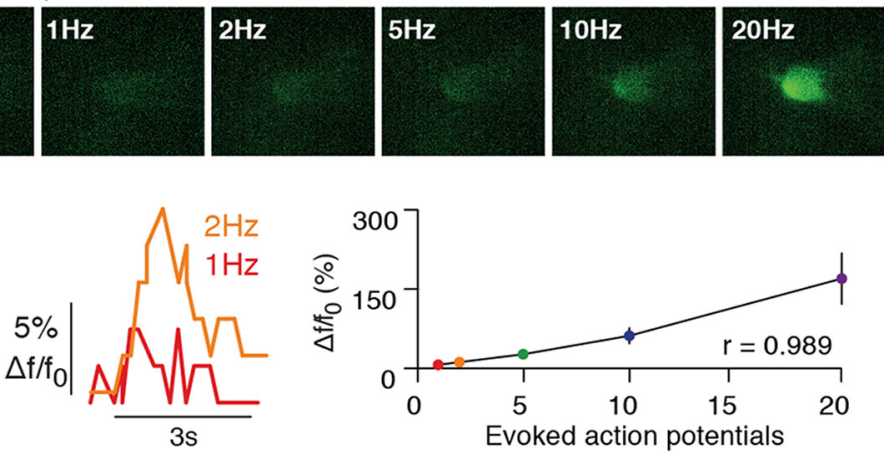

Figure 2. Detection in changes in neural activity in OT neurons. $\boldsymbol{A}$, Cre-inducible GCaMP6s was injected into the PVH of OT-Ires-Cre mice. $\boldsymbol{B}, 20 \times$ confocal images show colocalization of GCaMP6s with OT. C, Colocalization of GCaMP6s with OT immunohistochemistry. D, Example traces showing a series of depolarizing pulses (1-20 Hz) applied in current-clamp mode to drive trains of action potentials (bottom), during which GCaMP6s fluorescence was visualized in recorded neurons (top). $\boldsymbol{E}$, Action potential generation resulted in linear elevations in GCaMP6s fluorescence ( $n=8$ neurons; $n=2$ mice).

gation. Finally, administration of $\mathrm{CNO}$ did not alter the total distance traveled (Gq-DREADD: $t$ test, $t_{(5)}=0.87, p=0.42$; GiDREADD, $t$ test, $\left.t_{(6)}=0.18, p=0.99\right)$ (Fig. $\left.1 C, D\right)$ or velocity $(\mathrm{Gq}-$ DREADD, $t$ test, $t_{(5)}=0.67, p=0.45$, Gi-DREADD, $t$ test, $t_{(6)}=$ $0.10, p=0.93$ ) indicating that the effect of CNO was specific to social function and not a result of alterations in locomotor activity.

\section{Exposure to social stimuli induces activation of PVH-OT neurons}

Although it has been hypothesized that social stimulus exposure activates the OT system to promote appropriate social-behavioral responses (Shamay-Tsoory and Abu-Akel, 2016), socially induced activation of OT neurons has not been directly demonstrated. A lack of evidence for such responses is primarily related to the inability to record from these neurons in an awake behaving animal. To circumvent these limitations, we combined use of a GECI with in vivo 2-photon microscopy to visualize and monitor the activity of PVH-OT neurons located in the PVH.

To selectively target OT neurons, a virus encoding Creinducible GCaMP6s was injected into the PVH of OT-Cre mice, resulting in the selective expression of GCaMP6s in PVH-OT neurons (Fig. 2A-C). Whole-cell patch-clamp recordings demonstrated that evoked action potential firing correlated with increases in GCaMP mediated fluorescence in brain slices (Pearson, $r_{(3)}=0.989, p=0.001$, Fig. $\left.2 D, E\right)$. To visualize the activity of these neurons in vivo, a GRIN lens was implanted directly above the PVH and 2-photon calcium imaging was conducted in awake, head-fixed subjects (Fig. 3A-C), starting at $\sim 3-4$ weeks after lens implantation. Each imaging session lasted $15 \mathrm{~min}$ and was com- posed of a 5 min stimulus exposure period flanked by two $5 \mathrm{~min}$ periods without stimulus delivery (Fig. 3C).

To determine whether social stimuli exposure modulated the activity of PVH-OT neurons, each subject was exposed to either a social (anesthetized juvenile) or nonsocial (plastic bottle) stimulus on separate imaging sessions. Behavioral studies confirmed that, similar to an awake juvenile stimulus, adult male mice prefer to investigate an anesthetized juvenile stimulus compared with a nonsocial stimulus ( $t$ test, $t_{(7)}=6.78, p=0.0003, n=8$ mice) (Fig. $3 D, E$ ). There was no difference in the amount of time spent in each location of the chamber (one-way ANOVA, $F_{(2,21)}=2.08$, p 0.15).

During in vivo imaging sessions, the presentation of a social stimulus resulted in an increase in the activity of PVH-OT neurons compared with presentation of the nonsocial stimulus (Wilcoxon signed-rank test, $\left.\mathrm{W}_{(102)}=1556, p=0.0004\right)($ Fig. $3 F-H)$, with $52 \%$ of recorded neurons showing an increase in activity in response to the social stimulus and only $32 \%$ of neurons showing an increase in activity in response to the nonsocial stimulus (Fig. $3 I$ ). Presentation of the nonsocial stimulus also resulted in a greater proportion of PVH-OT neurons showing a decrease (52\%) in activity compared with the social stimulus (35\%) (102 neurons from $n=8$ mice) (Fig. $3 I$ ). This increase in activity is likely related to an increase in event rate as exposure to the social stimulus significantly increased event rate (two-way ANOVA, $F_{(2,606)}=8.159, p=0.0003$. Sidak's multiple-comparisons test between conditions: Pre $t_{(606)}=0, p=0.999$; Stim $t_{(606)}=5.646$, $p<0.0001$; Post $\left.t_{(606)}=3.575, p=0.0011\right)($ Fig. $3 J)$, but did not significantly alter event amplitude (two-way ANOVA, $F_{(2,589)}=$ 
A

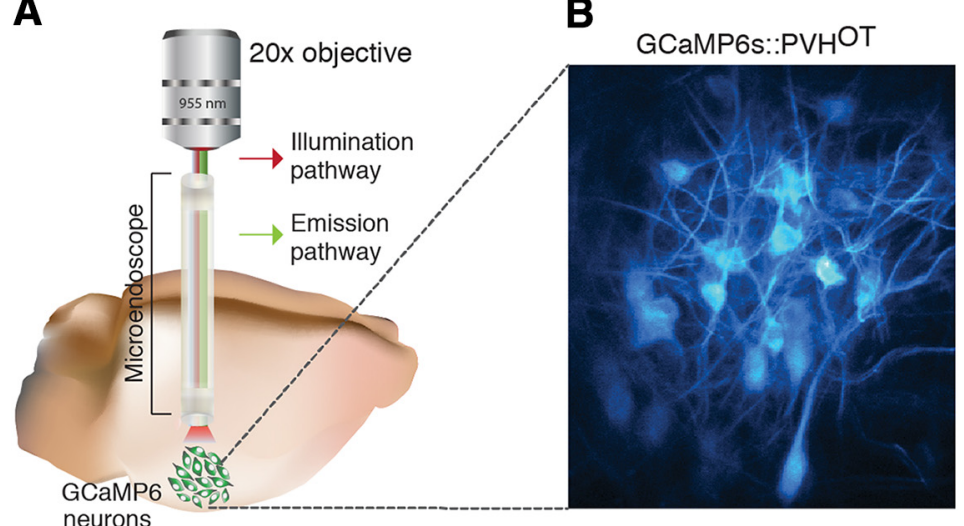

C

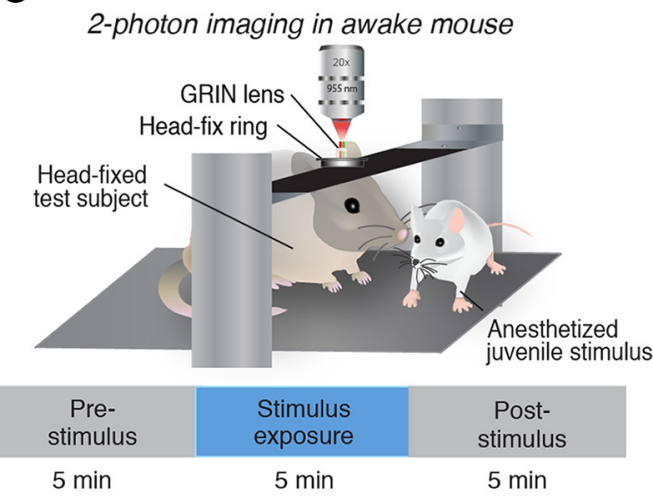

D

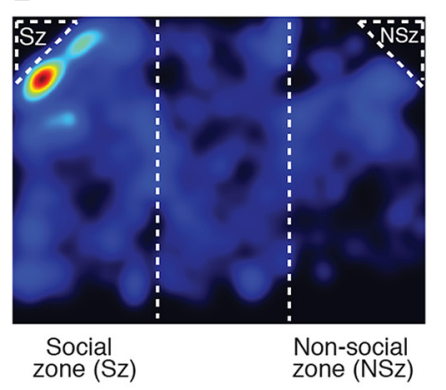

G

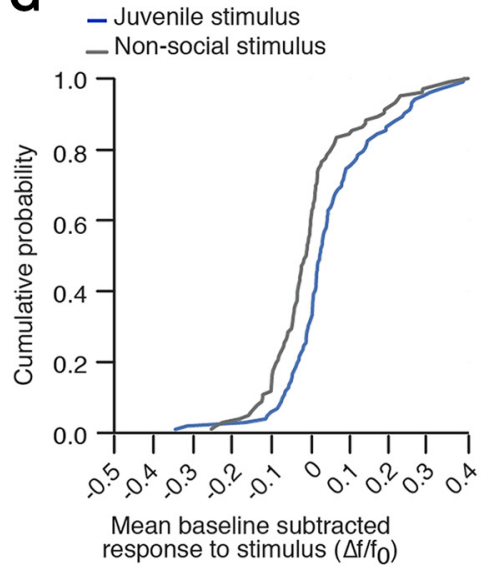

J

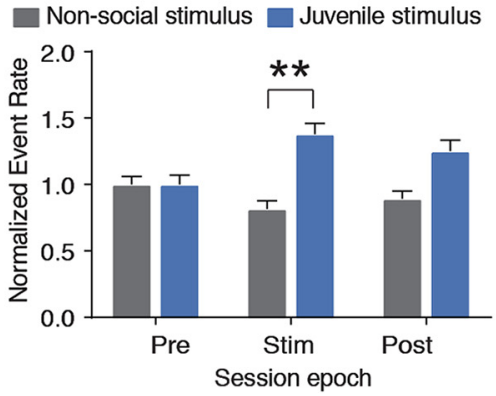

E

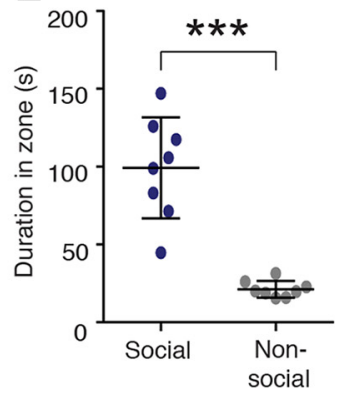

H

Mean baseline subtracted response per neuron $\left(\Delta \mathrm{f} / \mathrm{f}_{0}\right)$

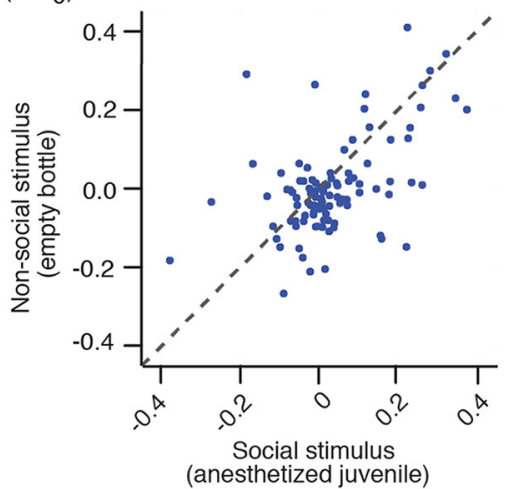

K

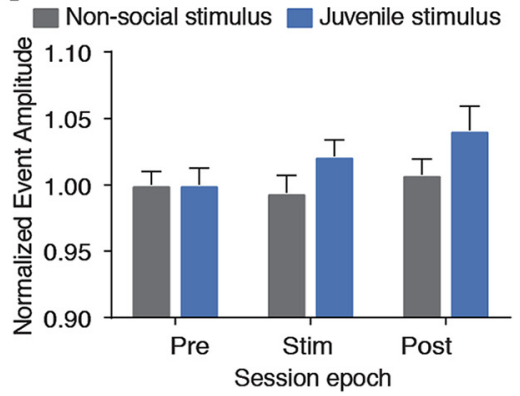

$\mathbf{F}$

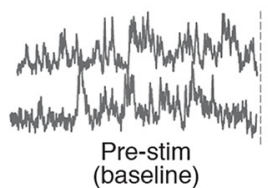

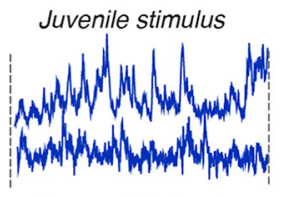

Non-social stimulus
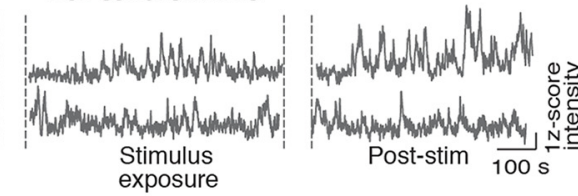

I
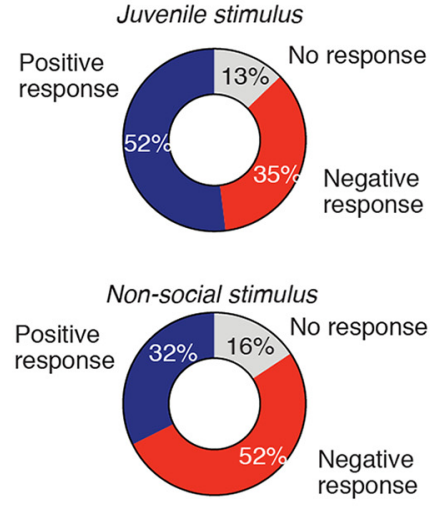

$\mathbf{L}$

Non-social stimulus Juvenile stimulus

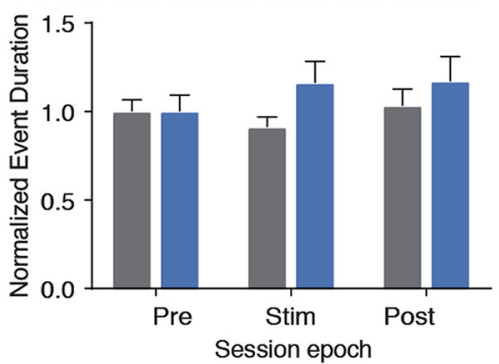

Figure 3. Social stimuli increase activity of a subpopulation of PVH-OT neurons. A, A GRIN lens was implanted above the PVH and a $20 \times$ objective was used to visualize calcium changes in PVH-0T neurons. B, SD projection of GCaMP6s expressing PVH-OT neurons. C, Diagram of 2-photon imaging experiments in an awake, head-fixed mouse. D, Representative activity heat map from a wild-type mouse investigating stimulus chambers containing either and anesthetized juvenile (social zone, left) or a plastic bottle (nonsocial zone, right). $\boldsymbol{E}$, Mice show a strong preference for investigating the anesthetized juvenile (social stimulus) over the empty bottle (nonsocial stimulus) $(n=8)$. $\boldsymbol{F}$, Representative calcium traces following exposure to the social stimulus (top) or the nonsocial stimulus (bottom). G, A greater proportion of PVH-OT neurons showed increases in activity to the social stimulus, while a greater proportion of PVH-OT neurons showed decreases in activity to the nonsocial stimulus. $\boldsymbol{H}$, Scatter plots showing mean baseline subtracted activity for each neuron to the social ( $x$-axis) and nonsocial ( $y$-axis) stimulus for each neuron. $I$, Functional classification of $0 \mathrm{~T}$ neurons following exposure to either a social or nonsocial stimulus. $\boldsymbol{J}-\boldsymbol{L}$, Exposure to a social stimulus increased the $(\boldsymbol{J})$ event rate of PVH-0T neurons, but did not alter $(\boldsymbol{K})$ event amplitude or (L) or event amplitude. ${ }^{* *} p \leq 0.005,{ }^{* * *} p \leq 0.0005$. 
A

Positive response to social stimulus Negative response to social stimulus No response to social stimulus

Positive response to non-social stimulus

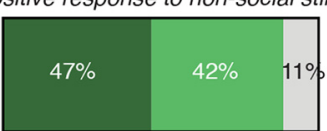

B

Negative response to non-social stimulus

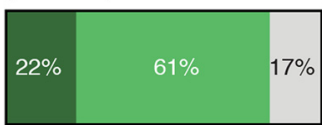

C No response to non-social stimulus

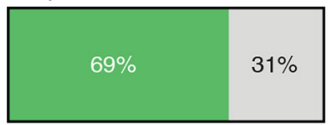

Figure 4. Characterization of PVH-OT neuron activity to social and nonsocial stimulus. $\boldsymbol{A}-\boldsymbol{C}$, Neurons were first grouped by their response to the social stimulus (positive, negative, or no response) and the response profile of each of these groups of neurons was then determined for the nonsocial stimulus. $\boldsymbol{A}$, For neurons that responded with an increase in activity to the social stimulus, $47 \%$ of these neurons also showed an increase in activity to the nonsocial stimulus, $42 \%$ showed a decrease in inactivity, and $11 \%$ showed no change in activity. $\boldsymbol{B}$, For neurons that showed a negative response to the social stimulus, $22 \%$ of these neurons showed an increase an activity to the nonsocial stimulus, $61 \%$ exhibited a decrease in activity to the nonsocial stimulus, and $17 \%$ of these neurons did not change their activity. $C$, For neurons that did not change their activity upon presentation of the social stimulus, $69 \%$ of these neurons decreased their activity to the nonsocial stimulus and $31 \%$ did not have a change inactivity. None of these neurons responded with an increase in activity to the nonsocial stimulus.

0.900, $p=0.407$ ) (Fig. $3 K$ ) or duration (two-way ANOVA, $\left.F_{(2,589)}=0.794, p=0.4525\right)$ (Fig. $\left.3 L\right)$. Overall, these data indicate that PVH-OT neurons differentially encode social versus nonsocial stimuli as a population. Preferential activation of PVH-OT neurons by social stimuli may play a critical role in encoding a stimulus as social and subsequently directing investigatory behavior toward social stimuli and away from nonsocial stimuli in the environment.

To further characterize the response profile of PVH-OT neurons, we next determined whether the neurons that responded positively to the social stimulus were the same group of neurons that also responded positively to the nonsocial stimulus. Of the neurons that showed a positive response to the social stimulus, $47 \%$ of these neurons also responded positively to the nonsocial stimulus, $42 \%$ showed a negative response to the nonsocial stimulus, and $11 \%$ did not respond to the nonsocial stimulus (Fig. $4 A$ ). Thus, there are subsets of PVH-OT neurons that exhibit opposing responses to social and nonsocial stimuli (socially specific), while a subset of neurons respond with an increase in activity to either stimulus (nonspecific). For neurons that responded negatively the social stimulus, $22 \%$ of these neurons exhibited a positive response the nonsocial stimulus, 61\% exhibited a negative response, and $17 \%$ exhibited no response. Finally, for neurons that did not respond to the social stimulus, $69 \%$ of these neurons exhibited a negative response to the nonsocial stimulus and $31 \%$ showed no response to the nonsocial stimulus. None of the neurons responded with an increase in activity to the nonsocial stimulus (Fig. 4C).

\section{PVH-OT neurons display a heterogenous pattern of firing}

Previous in vivo recordings from putative OT neurons located in the PVH of awake rodents have indicated that these neurons display a heterogeneous pattern of firing activity that can be assigned to one of three categories: silent to slow irregular, fast continuous, or phasic firing cells (Poulain and Wakerley, 1982). However, it should be noted that the spontaneous activity of putative OT neurons has rarely been classified as phasic as this pattern of activity is primarily associated with lactation and birth (Summerlee and Lincoln, 1981; Summerlee, 1981). Thus, under most physiological conditions, putative OT neurons have typically been classified as either firing at a very slow rate or in a fast continuous pattern (Brimble et al., 1978; Moos et al., 2004; Sabatier and Leng, 2006). We therefore determined whether the population of PVH-OT neurons we imaged exhibited a heterogeneous pattern of spontaneous activity that could be used to further classify these neurons into subpopulations.

To classify PVH-OT neurons by their spontaneous baseline activity, the mean power across all recorded frequencies during the $5 \mathrm{~min}$ baseline period was calculated as the mean squared absolute values of the fast fourier transform (FFT). Neurons were then sorted and ranked by their mean power (Fig. 5A) and the difference between two consecutively ranked neurons was calculated to approximate the "knee" in the plot by a setting a threshold difference to the median plus two times the interquartile range of the distribution of power differences (Fig. $5 B$ ). The knee was used to define the boundary between high/low power neurons. This resulted in 67 of 102 neurons to be classified as low powered (66\%) and 35 to be classified as high powered (34\%). We next determined whether classified high and low-powered neurons differed in their response to social and nonsocial stimuli.

Indeed, the response of individual PVH-OT neurons to social and nonsocial stimuli varied as a function of their spontaneous activity levels. In general, low-power PVH-OT neurons responded primarily with increases in activity to the social stimulus and decreases in activity to the nonsocial stimulus (Wilcoxon signed-rank $t$ test, $t_{(67)}=490, p=0.00005$ ) (Fig. 5C,D), while high-power PVH-OT neurons tended to show similar response patterns to both the social and nonsocial stimuli (Wilcoxon signed-rank $t$ test, $t_{(35)}=278, p=0.54$ ) (Fig. $5 E, F$ ). Thus, PVH-OT neurons are composed of a heterogeneous population of neurons in which low-power neurons show more robust encoding of social stimuli. This group of neurons is likely similar to OT neurons characterized in previous studies as silent or firing in a slow irregular pattern (Poulain and Wakerley, 1982).

We next determined whether neurons classified as high and low power that responded with a significant increase or decrease in activity to the social stimulus were the same neurons that also responded with significant changes in activity to the nonsocial stimulus. Among OT-PVH neurons classified as low power and that exhibited a positive response to the social stimulus, 34\% of these neurons also exhibited a positive response to the nonsocial stimulus, while $54 \%$ of these neurons exhibited a negative response and $12 \%$ did not show a change in activity (Fig. 6A). For high-power neurons that exhibited a positive response to the social stimulus, $72 \%$ of these neurons also responded positively to the nonsocial stimulus, $17 \%$ of neurons exhibited a decrease in activity, and $11 \%$ of neurons did not show a change in activity to the nonsocial stimulus (Fig. $6 \mathrm{~B}$ ). Thus, a greater proportion of low power PVH-OT neurons responded with an increase in activity selectively to the social stimulus, while high-power neurons tended to respond nonselectively with increases in activity to both types of stimuli. For low-power PVH-OT neurons that exhibited a decrease in activity to the social stimulus, $21 \%$ of these neurons increased activity in response to the nonsocial stimulus, $67 \%$ decreased activity in response to the nonsocial stimulus, and $12 \%$ of neurons did not respond to the nonsocial stimulus (Fig. $6 C)$. For high-power neurons that decreased activity to the social 
A

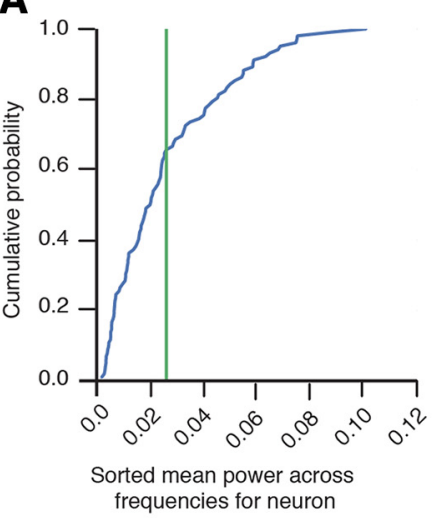

C

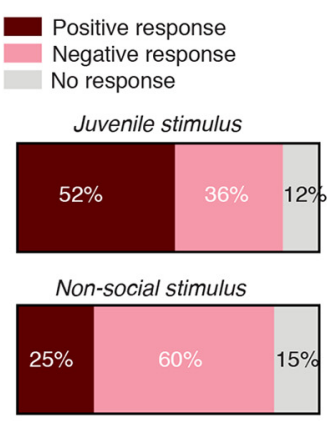

E

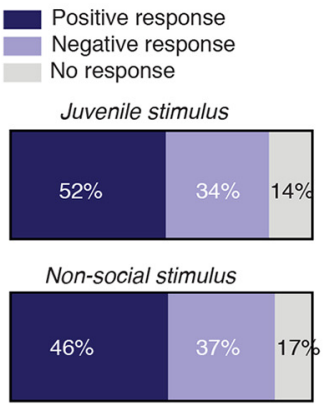

B

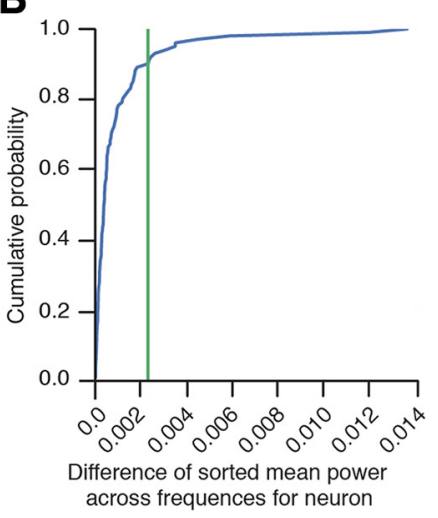

\section{D}

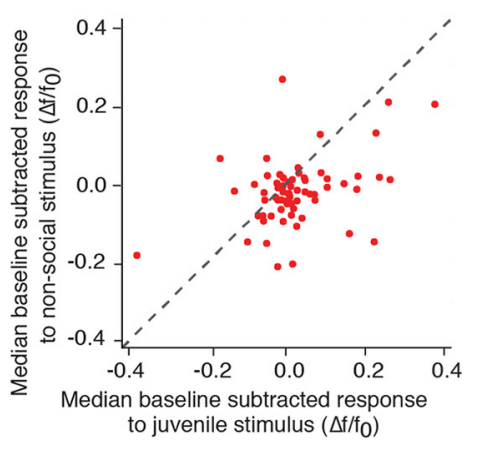

$\mathbf{F}$

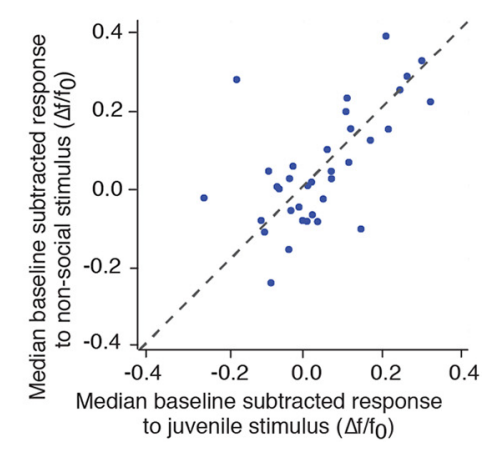

Figure 5. Heterogeneous activity patterns in PVH-OT neurons. A, Cumulative probability distribution plots of sorted mean power across frequency. Green line indicates location of "knee" found in $\boldsymbol{B}$. B , Cumulative probability distribution plot of difference between each neuron sorted by mean power. C, PVH-OT neurons categorized as low-power neurons primarily responded to increases in activity to the social stimulus and decreases in activity to the nonsocial stimulus. $\boldsymbol{D}$, Scatter plot showing the mean baseline subtracted response to the social ( $x$-axis) and nonsocial stimulus ( $y$-axis) for individual low-power neurons. $\boldsymbol{E}$, High-power PVH-OT neurons showed similar activity patterns to the social and nonsocial stimulus. $F$, Scatter plot showing the mean baseline subtracted response to the social and nonsocial stimulus for individual high-power neurons.

stimulus, $25 \%$ of these neurons showed an increase in activity to the nonsocial stimulus, $50 \%$ decreased activity, and $25 \%$ of neurons did not show a change in activity (Fig. 6D). Finally, for both high and low-power neurons that did not show a change in activity to the social stimulus, neither of these groups of PVH-OT neurons responded to the nonsocial stimulus with an increase in activity (Fig. 6E,F).

\section{Oxytocin neurons and the encoding on nonsocial appetitive stimuli}

It has been hypothesized that one mechanism by which OT may promote social behavior is by encoding social stimuli as reward- ing (Dölen et al., 2013). Thus, to determine whether increases in PVH-OT neuron activity were selective to social stimuli, we measured the activity of PVH-OT neurons in response to exposure to a nonsocial appetitive stimulus, sucrose. Unlike exposure to a social stimulus, consumption of randomly administered sucrose (100 trials/session) did not result in increases in PVH-OT neuron activity as $89 \%$ of neurons were unresponsive and $11 \%$ of neurons showed decreases in their activity (data from 105 neurons recorded from $n=3$ mice) (Fig. $7 A, C$ ). This response was not due to a novelty effect as a similar response pattern was seen on a second day of sucrose exposure with $96 \%$ of neurons showing no response, $3 \%$ of neurons showing a negative response, and only $1 \%$ of neurons showing an increase in activity (Fig. $7 B, D$ ). Overall, these data suggest that PVH-OT neurons show preferential increases in their activity to social stimuli compared with an appetitive nonsocial stimulus.

\section{OT receptor agonist rescues social deficits in Shank $3 b^{-/-}$mice}

A failure to attend to socially salient stimuli in the environment is a core symptom of ASD (Ozonoff et al., 2010; Chevallier et al., 2012). For example, individuals with autism often fail to orient their gaze toward relatives or peers, prefer to interact with objects over people, and fail to show interest in conversation with others (Kanner, 1968). We therefore used a mouse model of autism, Shank $3 b \mathrm{KO}$ mice (Peça et al., 2011), to determine whether defects in the OT system contribute to impaired social functioning in Shank3b KO mice. Indeed, Shank $3 b^{-1-}$ mice showed a marked reduction in the number of immunopositive OT neurons within the medial region of the $\mathrm{PVH}$ (two-way ANOVA, $F_{(2,85)}=53.87, p<0.0001, n=3-4$ mice/ group) compared with both wild-type (WT) (Tukey's post hoc test, $p=0.0004$ ) and heterozygous littermates (Tukey's post hoc test, $p=0.005$ ) (Fig. $8 A-D$ ). This reduction was specific to the medial $\mathrm{PVH}$, where the density of OT neurons is the highest. Reductions were not identified within the rostral (WT vs Shank $3 b^{-1-}: p=0.96$, Shank $3 b^{-1-}$ vs Shank3b $b^{+1-}: p=0.46$ ) or caudal PVH (WT vs Shank $3 b^{-1-}: p=0.72$, Shank $3 b^{-1-}$ vs Shank3b $\left.b^{+l-}: p=0.32\right)$ (Fig. $8 D$ ). Additionally, heterozygous littermates, which do not exhibit impairments in social behavior did not differ from WT littermates in OT neuron density within any region of the PVH (Tukey's post hoc test, rostral: $p=0.3$, medial: $p=0.99$, caudal: $p=0.11)($ Fig. 8D).

We next determined whether the impaired social behavior phenotype in Shank3b KO could be rescued through pharmaco- 
logical activation of the OT system. Consistent with previous findings (Peça et al., 2011), Shank3b KO mice receiving i.p injections of saline (control) did not show a preference for social stimulus investigation in the 3-chamber social choice task (two-way ANOVA, $F_{(1,36)}=14.51, p=$ 0.0005 ; Bonferroni's post hoc test, $p=1.0$, $n=7$ /group) (Fig. 9A,B). However, Shank3b KO mice receiving i.p injections of either $10 \mathrm{mg} / \mathrm{kg}(p=0.01)$ or $30 \mathrm{mg} / \mathrm{kg}$ $(p=0.03)$ of an OT receptor agonist (Way267464) showed a significant preference for the social zone (Fig. 9A,B). These data indicate that social interaction deficits in mice with abnormal OT systems can be rescued by acute treatment with an OT receptor agonist. In contrast, heterozygous (two-way ANOVA, $F_{(1,48)}=$ 49.27, $p=0.0001$; Bonferroni's post hoc test, $0 \mathrm{mg} / \mathrm{kg}$ Way267464: $p=0.0005,10$ $\mathrm{mg} / \mathrm{kg}$ Way267464: $p=0.0022,30 \mathrm{mg} / \mathrm{kg}$ Way267464: $p=0.0001, n=9$ /group) (Fig. $9 C, D$ ) and WT littermates (twoway ANOVA, $F_{(1,42)}=44.32, p=$ 0.0001; Bonferroni's post hoc test, 0 $\mathrm{mg} / \mathrm{kg}$ Way267464: $p=0.001,10 \mathrm{mg} / \mathrm{kg}$ Way267464: $p=0.04,30 \mathrm{mg} / \mathrm{kg}$ Way267464: $p=0.0001, n=8 /$ group) showed a preference for the social stimulus regardless of the treatment group (Fig. $9 E, F$ ). Thus, acute administration of an OT receptor agonist does not alter the social preferences of mice with typical levels of sociability and with no identified abnormalities in their OT system. In addition, acute administration of an OT receptor agonist did not impact locomotor behavior (Fig. 9G-L) or the duration of time spent in any compartment of the chamber that did not directly include interaction zones (WT: two-way ANOVA, $F_{(2,21)}=1.51, p=$ 0.25 ; heterozygous: two-way ANOVA, $F_{(2,24)}=0.65, p=0.53$; homozygous: two-way ANOVA, $F_{(2,18)}=0.93, p=0.41$.

\section{Discussion}

$\mathrm{OT}$ is critical for the expression of a wide array of social behaviors (Gimpl and Fahrenholz, 2001; Kelly and Goodson, 2014); however, the specific function of this neuromodulator in social interactions is not well understood. By recording from PVH-OT neurons, we show that exposure to a social stimulus activates a subpopulation of these neurons in a manner that is distinct from nonsocial stimuli. Moreover, chemogenetic inhibition of PVH-OT neurons severely impaired social preference behavior. Together, these data suggest that OT neurons play a critical role in the encoding of socially specific stimuli and in guiding behavior toward such stimuli. Importantly, deficits in social attention are thought to contribute to the etiology of autism (Ozonoff et al., 2010) and we show that Shank $3 b$ KO mice have fewer OT neurons within the PVH and that treatment with OT rescues social deficits in these mice. Thus, therapeutic strategies designed to increase the activity of the OT system during social encounters may have significant value in the treatment of ASD.

\section{B}

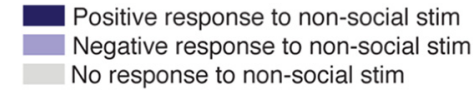

Positive response to social stimulus

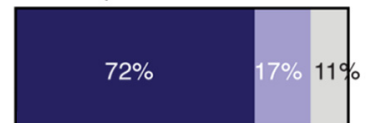

D

Negative response to social stimulus

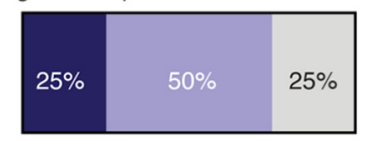

$\mathbf{F}$ response to social stimulus

$37 \%$

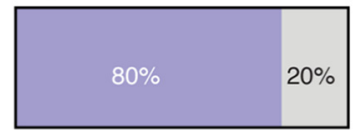

Figure 6. Characterization of PVH-OT neuron activity to social and nonsocial stimulus following categorization of neurons by their baseline activity. $\boldsymbol{A}$, For low-powered power neurons that responded with an increase in activity to the social stimulus, 34\%

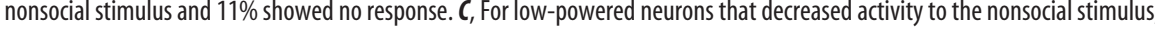
the nctivity, and 25\% showed no change in activity. $E$, For low-powered neurons that did thespond to the social stimulus, $63 \%$ decreased their activity to the nonsocial stimulus. None of these neurons responded with an increase in activity. $\boldsymbol{F}$, For high-powered neurons that did not exhibit a change in activity to the social stimulus, $80 \%$ decreased activity to the nonsocial stimulus and $20 \%$ did not show a change in activity. None of these neurons increased their activity.

\section{In vivo imaging of $\mathrm{OT}$ neurons in awake mice}

A prerequisite to studying the function of OT neurons is the ability to identify and record from these neurons in an awake, behaving animal. In mammals, OT neurons are found in several nuclei throughout the hypothalamus, such as the $\mathrm{PVH}-$ a heterogeneous brain structure containing a wide array of cell types including OT, vasopressin, corticotropin releasing hormone, thyrotropin releasing hormone, somatostatin, and kisspeptinexpressing neurons (Zhu et al., 2007; Della Torre et al., 2014). Given the large diversity of cell types within this region, many previous studies attempting to record from OT neurons have been limited by the ability to definitively identify these neurons (Poulain and Wakerley, 1982).

Attempts have been made to classify OT neurons based on anatomical and physiological properties. However, these attempts may result in neurons with similar projection targets or physiological evoked responses to be misclassified as OT neurons (Armstrong et al., 1994), result in only a proportion of OT neurons to be studied (Armstrong et al., 1994; Brown et al., 2008), and when pharmacological techniques for cell identification are used, these methods may induce alterations in the natural activity pattern of OT neurons (Sabatier et al., 2003). Moreover, many of these previous identification methods required the use of stimuli that robustly activate OT neurons (Brimble et al., 1978; Moos et al., 2004), such as suckling of a lactating female, which induces burst-like firing patterns (Summerlee and Lincoln, 1981; Belin et al., 1984) that may not be representative of OT neuron activity under other social contexts.

In the present study, we used a GECI in combination with methods for deep brain calcium imaging (Resendez and Stuber, 2015; Resendez et al., 2016) to visualize the activity of PVH-OT in response to the presentation of different types of environmental 
A

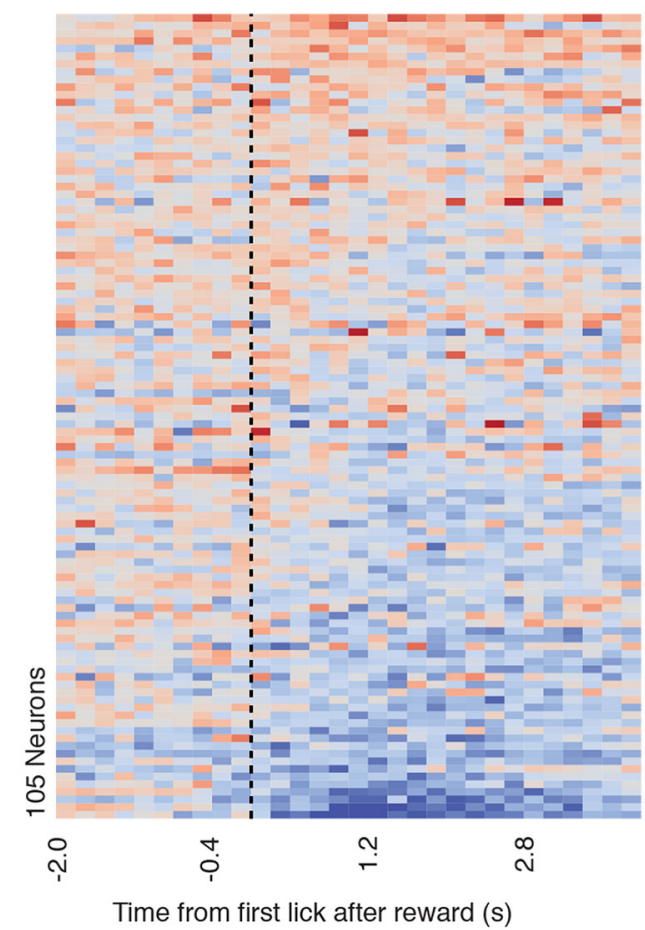

C

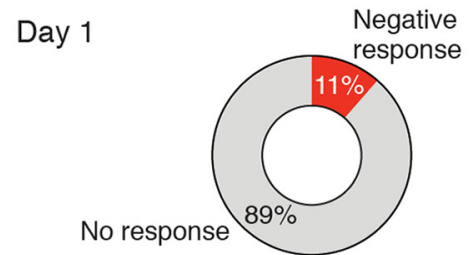

B
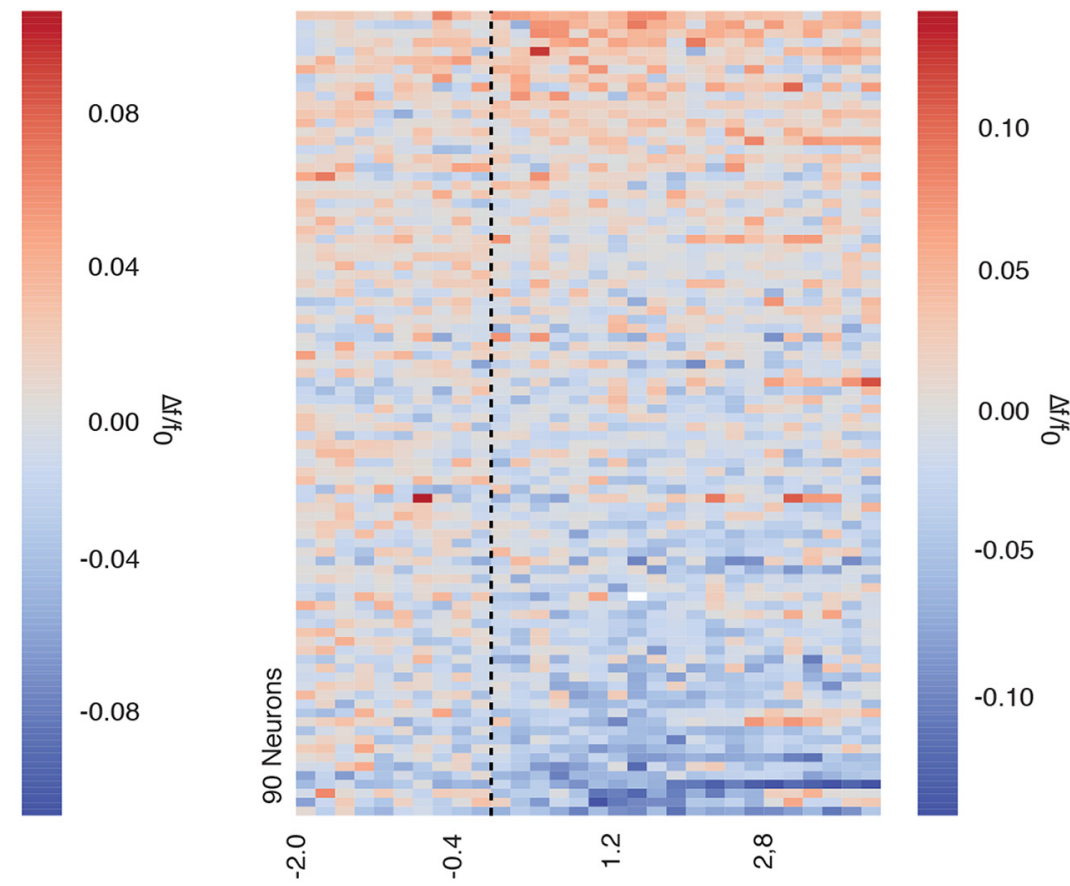

Time from first lick after reward (s)

D

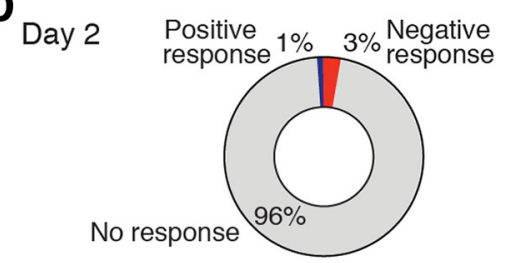

Figure 7. PVH-OT neurons do not respond to sucrose consumption. $A, B$, Activity heatmaps for all PVH-OT neurons following the consumption of randomly delivered sucrose on ( $A$ ) the first and (B) the second day of exposure. Each session consisted of 100 trials and the activity of each neuron was averaged across all trials for each session ( 3 mice, 105 neurons). $C$, On the first day of random sucrose delivery, none of the neurons showed positive responses to sucrose and $11 \%$ of neurons showed negative responses. $\boldsymbol{D}$, On the second day of sucrose delivery, only $1 \%$ of neurons showed positive responses to sucrose and $3 \%$ showed negative responses.
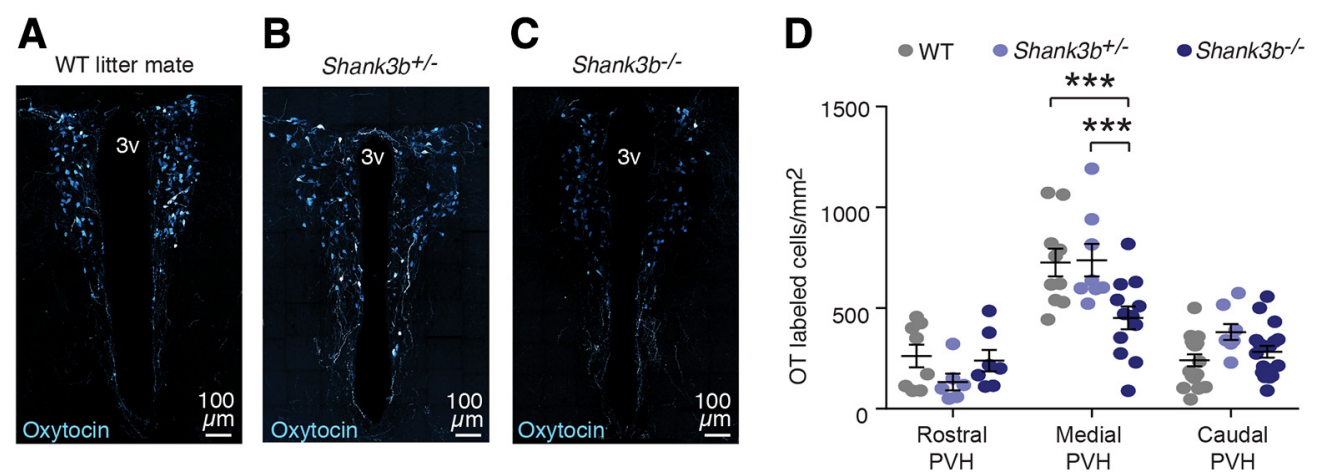

Figure 8. Shank $3 b^{-1-}$ show reduced numbers of PVH-OT neurons. $\boldsymbol{A}-\boldsymbol{C}, 40 \times$ confocal images of 0 T neurons in the medial PVH of $(\boldsymbol{A})$ WT, $(\boldsymbol{B})$ heterozygous $\left(\right.$ Shank $\left.3 b^{+/-}\right)$, and $(\boldsymbol{C})$ homozygous Shank3b K0 mice (Shank $\left.3 b^{-1-}\right)$. D, Shank3b ${ }^{-1-}$ have reduced numbers of 0T neurons within the medial PVH $\left(n=4-5\right.$ mice/group). ${ }^{* * *} p \leq 0.0005$.

stimuli. Compared with nonsocial stimuli, the presentation of a social stimulus evoked greater increases in PVH-OT neuron activity. This increase in activity was moderate, yet significant, and was sustained over the duration of the trial, which is consistent with the activity of OT neurons under conditions that do not induce burst firing. For example, systemic administration of cho- lecystokinin (CCK) (Luckman et al., 1994; Rossoni et al., 2008), dehydration (Moos et al., 2004), and hemorrhage (Poulain and Wakerley, 1982) all produce small graded increases in putative OT neuron activity that do not at all resemble bursting. Importantly, moderate and sustained increases in putative OT neuron activity are associated with the central release of OT (Sabatier et 
A
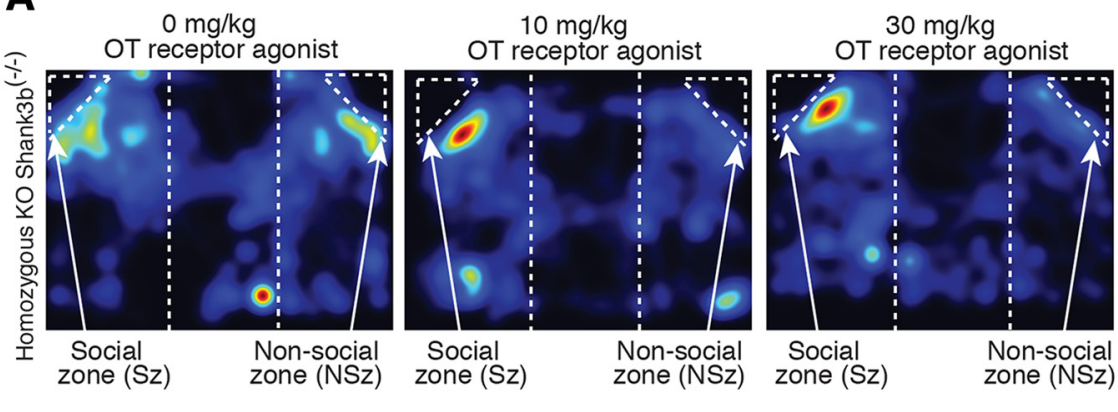

C

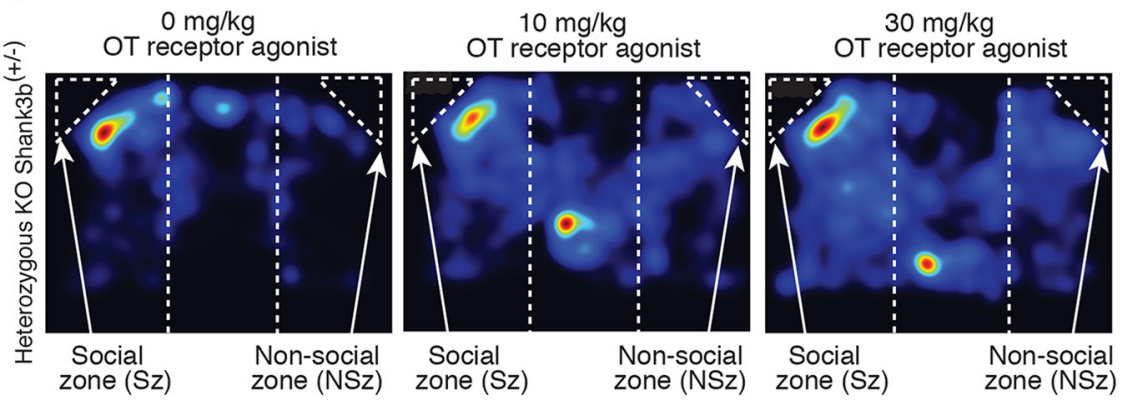

$\mathbf{E}$

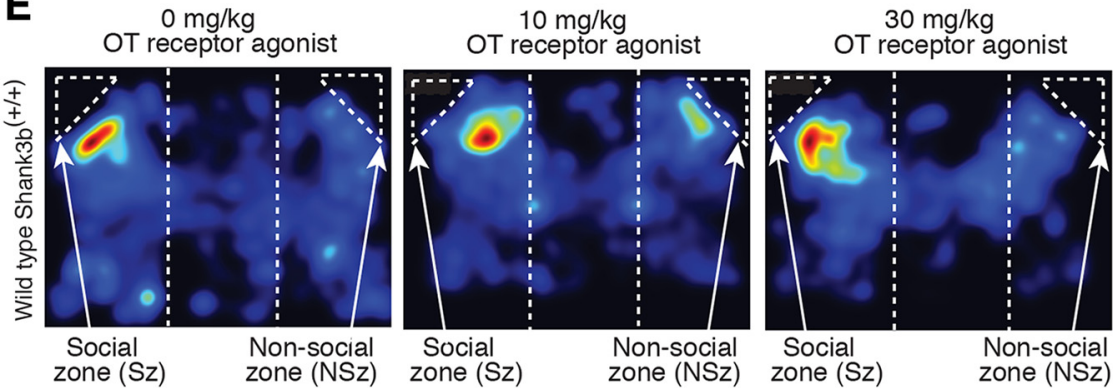

B

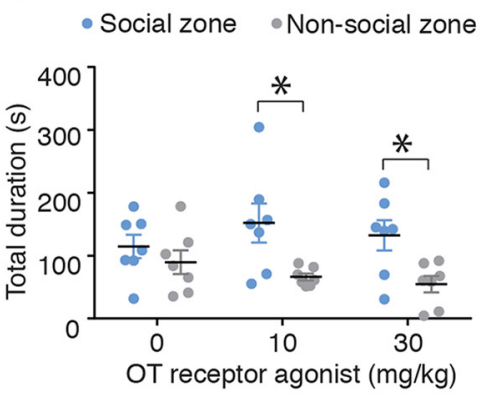

D

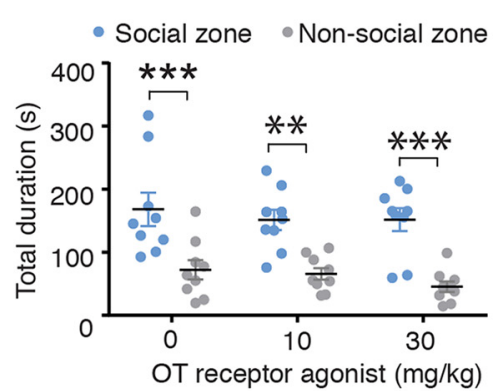

$\mathbf{F}$

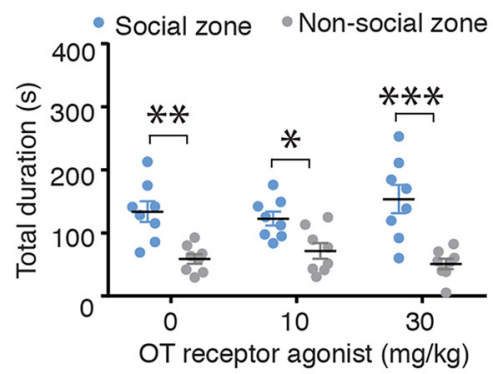

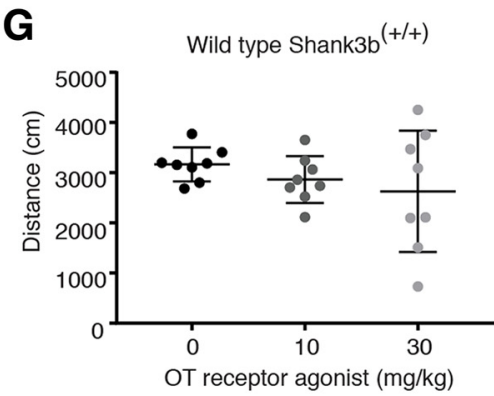

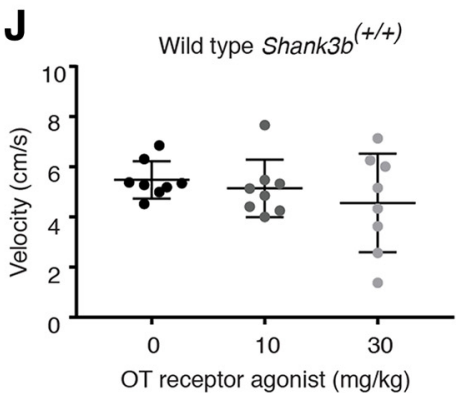

H Heterozygous KO Shank3b ${ }^{(+/)}$

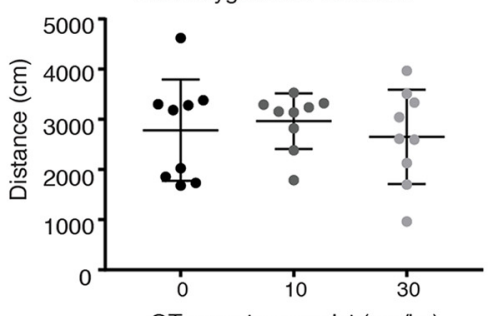

OT receptor agonist $(\mathrm{mg} / \mathrm{kg})$

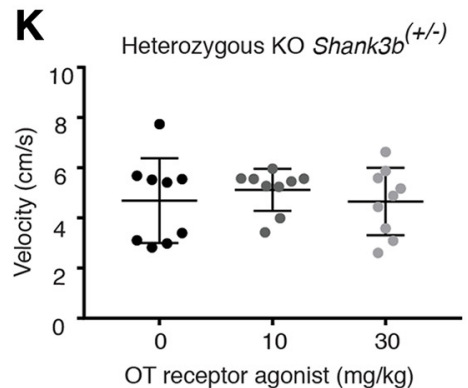

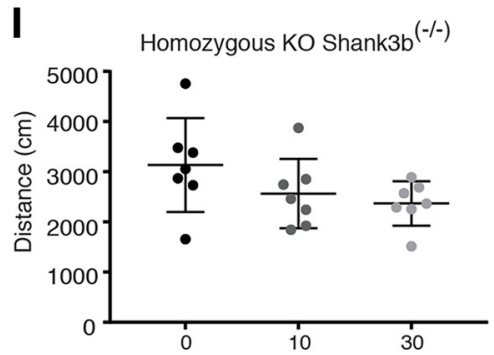

OT receptor agonist $(\mathrm{mg} / \mathrm{kg})$

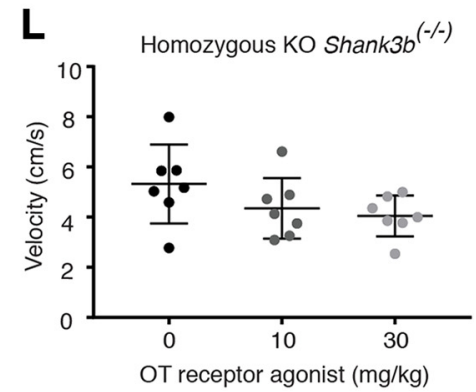

Figure 9. Oxytocin receptor agonist rescues social deficit in Shank3b K0 mice. $\boldsymbol{A}$, Representative activity heat maps from Shank3b- $1-$ mice (homozygous K0) receiving injections of either vehicle, $10 \mathrm{mg} / \mathrm{kg}$ of an $0 \mathrm{~T}$ receptor agonist, or $30 \mathrm{mg} / \mathrm{kg}$ of an $0 \mathrm{~T}$ receptor agonist before social choice testing. B, Peripheral administration of an $0 \mathrm{~T}$ receptor agonist restored social deficits in Shank $3 b^{-1-}$ mice ( $n=7 /$ group). C, Representative activity heat maps from Shank ${ }^{+/-}$mice (Heterozygous KO) receiving injections of either saline, $10 \mathrm{mg} / \mathrm{kg}$ of an (Figure legend continues.) 
al., 2003), while burst firing of OT neurons is associated with bolus release of OT into the bloodstream (Summerlee and Lincoln, 1981; Israel et al., 2003). Thus, it is possible that graded continuous release of OT into the brain is important for priming and maintaining social behavior, while pulsatile release of OT into the bloodstream may be more critical for regulating muscle contraction during lactation and birth.

Previous studies have identified that agents that trigger the mobilization of intracellular calcium within OT neurons can exert opposing effects on central and peripherally released OT (Sabatier and Leng, 2006; Ludwig and Leng, 2006). For example, central administration of the melanocortin 4 receptor (MC4R) agonist, $\alpha$-MSH, increases the central release of OT by mobilizing intracellular calcium stores (indicated by an increase in fluorescence activity under conditions of low extracellular calcium), while at the same time decreasing peripheral release of OT from terminals by reducing the firing rate of OT neurons (Sabatier et al., 2003). Thus, central and peripheral release of OT can be regulated independently and by different mechanisms (Moos et al., 2004). Interestingly, $\alpha$-MSH, which increases central release of OT through elevations in intracellular calcium, has been shown to have prosocial effects on behavior that occurs through an OT receptor-dependent mechanism (Modi et al., 2015).

\section{Shank $3 b^{-1-}$ mutant mice exhibit social deficits and reduced OT immunostaining}

Shank3 protein is found postsynaptically at glutamatergic synapses where it plays a critical role in excitatory synapse formation and plasticity (Jiang and Ehlers, 2013). Early in development, expression of this protein occurs widely throughout the rodent brain, but 2 weeks following birth, Shank3 expression becomes restricted, with the highest densities occurring in the cortex, striatum, and hippocampus (Böckers et al., 2001; Peça et al., 2011). For this reason, many studies to date have focused on the impact of Shank3 mutations on neuronal function within these brain regions. In Shank3 mouse models with deletions of the exons encoding the PDZ binding domain $\left(\right.$ Shank $\left.3 B^{-/-}\right)$, a reduction in corticostriatal connectivity has been identified, which is thought to partially underlie the high levels of repetitive behaviors displayed by these animals (Peça et al., 2011; Peixoto et al., 2016). In addition, in mouse models containing mutations in other regions of the Shank3 gene, such as those with insertion of a transcriptional stop cassette upstream of the PDZ domain coding exons, impairments in hippocampal transmission and plasticity have been reported as well as deficits in performance in a Morris water maze task (Jaramillo et al., 2017). Importantly, these same behavioral and neural abnormalities were not identified in Shank $3 b^{-1-}$ mice (Peça et al., 2011). Thus, the neural and behavioral manifestation of Shank3 mutations is likely depen-

\section{$\leftarrow$}

(Figure legend continued.) $\quad 0 \mathrm{~T}$ receptor agonist, or $30 \mathrm{mg} / \mathrm{kg}$ of an $0 \mathrm{~T}$ receptor agonist before social choice testing. $\boldsymbol{D}$, Peripheral administration of an $0 \mathrm{~T}$ receptor agonist did not alter social preferences in heterozygous KO mice $(n=9)$. $\boldsymbol{E}$, Representative activity heat maps from Shank ${ }^{+/+}$mice (WT) receiving injections of either saline, $10 \mathrm{mg} / \mathrm{kg}$ of an $0 \mathrm{~T}$ receptor agonist, or $30 \mathrm{mg} / \mathrm{kg}$ of an $0 \mathrm{~T}$ receptor agonist before social choice testing. $\boldsymbol{F}$, Peripheral administration of an $0 \mathrm{~T}$ receptor agonist did not alter social preferences in WT $(n=8)$ mice. $(\mathbf{G}-\boldsymbol{l})$ During the social choice test, peripheral administration of oxytocin receptor agonist did not impact the total distance traveled in $(\boldsymbol{G})$ wild-type $\left(F_{(2,21)}=0.42, p=0.66, n=8\right)$, $(\boldsymbol{H})$ heterozygous $\left(F_{(2,24)}=0.30, p=0.74, n=9\right)$, or $(I)$ homozygous KO mice $\left(F_{(2,18)}=2.15, p=0.15, n=7\right)$. $(\boldsymbol{J}-\boldsymbol{L})$ There was also no effect on velocity during the social choice test in $(J)$ wild-type $\left(F_{(2,21)}=\right.$ $0.91, p=0.45, n=8),(K)$ heterozygous $\left(F_{(2,24)}=0.33, p=0.72, n=9\right)$, or $(\boldsymbol{L})$ homozygous K0 mice $\left(F_{(2,18)}=2.03, p=0.16, n=7\right) .{ }^{*} p \leq 0.05,{ }^{* *} p \leq 0.005,{ }^{* * *} p \leq 0.0005$. dent on the specific type of mutation as well as the location of this mutation within the gene. Understanding the sum of neural systems impacted by Shank3 mutations will be critical for developing new pharmacological targets for the treatment of ASDs.

In the present study, we show that mutations within the Shank $3 b$ gene influence neural systems outside of the cortex and striatum. To our knowledge, this is the first time that a manipulation of the Shank3 gene has been shown to lead to alterations in hypothalamic OT neurons. Specifically, we show that ShankbB $B^{-1-}$ mice have significantly fewer immunopositive OT neurons within the medial PVH. This finding is particularly interesting given that in the present study we also show that exposure to a social stimulus induces activation of PVH-OT neurons and that activation of these neurons is required for the proper expression of social behavior. Thus, it is possible, that these deficits are at least mediated by abnormal functioning of the OT system and that the development of therapeutics that directly target the OT system may provide novel treatments for social impairments in ASDs. In the Shank $3 b^{-1-}$ mice used in this study, acute administration of an OT receptor agonist was indeed sufficient to rescue social impairments in adult subjects, further supporting a valuable role for OT in ASD therapeutics. Moreover, deficits in both the OT system and social behavior have been reported in two other models of autism, the hyperserotonemia model of autism (McNamara et al., 2008; Martin et al., 2012) and the Cntnap2 mouse model (Peñagarikano et al., 2015). In the Cntnap2 model, early treatment with OT was sufficient to rescue reduced OT immunoreactivity as well as social functioning, suggesting that there may be a critical developmental time window for optimal treatment (Peñagarikano et al., 2015).

Head-fixed imaging methods and the study of social behavior The activity of individual PVH-OT neurons were monitored with 2-photon imaging methods through a chronically implanted GRIN lens. While these methods enabled the activity pattern of these neurons in response to the presentation of a social stimuli to be visualized for the first time, the necessity of a head-fixed behavioral set up poses some limitations for studies of social behavior. More specifically, the restrictive nature of the head-fix behavioral apparatus prevents the test subject from following and engaging with a freely moving social conspecific. As a result, an anesthetized social conspecific was chosen as the stimulus subject. Our behavioral studies indicated that when given the choice between an anesthetized juvenile stimulus or an empty behavioral chamber, test subjects preferred interacting with the anesthetized social stimulus over the empty chamber, similar to behavioral results with an awake stimulus. In addition, it has been shown that an anesthetized social stimulus was as effective as an awake social stimulus in the reduction of fear responses in rats (Marina and Bauermeister, 1974) and that rat mothers will approach anesthetized pups; however, they were shown to engage with them for shorter durations than awake vocalizing pups (Okabe et al., 2013). Similarly, rats show higher levels of engagement with an anesthetized social conspecific compared with a nonsocial stimulus but showed the highest level of engagement with an awake social stimulus compared with an anesthetized social stimulus. Together, these results indicate that while an anesthetized social stimulus is sufficient to provoke social engagement among test subjects, it may not be the most potent stimulus.

\section{Conclusion}

Orienting toward social information early in life is critical for the proper development and expression of species typical social be- 
havior. Interestingly, during periods of development in which sensory systems come on line, there is a robust and transient increase in the expression of OTRs (Hammock, 2015; Mitre et al., 2016) suggesting that the OT system may play a critical role in organizing the brain to be receptive to social stimuli. In the adult brain, it is known that OT acts in sensory processing regions of the brain to enhance signal-to-noise processing in a socially specific manner (Marlin et al., 2015; Oettl et al., 2016), but it is unknown whether similar mechanisms occur in the developing brain, and if those mechanisms may be necessary for the proper development of social circuits. OT neurons have also been shown to project to reward processing regions of the brain and it is hypothesized that one mechanism in which OT promotes social behavior is through the encoding of social stimuli as rewarding (Hung et al., 2017). Future studies examining the role of the OT system in the development of social brain circuits as well as which aspects of social behavior are influenced at each developmental stage will be necessary to guide the development of targeted interventions for the treatment of social pathologies, such as ASDs.

\section{References}

Alexander GM, Rogan SC, Abbas AI, Armbruster BN, Pei Y, Allen JA, Nonneman RJ, Hartmann J, Moy SS, Nicolelis MA, McNamara JO, Roth BL (2009) Remote control of neuronal activity in transgenic mice expressing evolved G protein-coupled receptors. Neuron 63:27-39.

Anacker AM, Christensen JD, LaFlamme EM, Grunberg DM, Beery AK (2016) Septal oxytocin administration impairs peer affiliation via V1a receptors in female meadow voles. Psychoneuroendocrinology 68:156162.

Armstrong WE, Smith BN, Tian M (1994) Electrophysiological characteristics of immunochemically identified rat oxytocin and vasopressin neurones in vitro. J Physiol 475:115-128.

Bachner-Melman R, Ebstein RP (2014) The role of oxytocin and vasopressin in emotional and social behaviors. Handb Clin Neurol 124:53-68.

Bales KL, Perkeybile AM (2012) Developmental experiences and the oxytocin receptor system. Horm Behav 61:313-319.

Bales KL, Saltzman W (2016) Fathering in rodents: neurobiological substrates and consequences for offspring. Horm Behav 77:249-259.

Bartz JA, Zaki J, Bolger N, Ochsner KN (2011) Social effects of oxytocin in humans: context and person matter. Trends Cogn Sci 15:301-309.

Belin V, Moos F, Richard P (1984) Synchronization of oxytocin cells in the hypothalamic paraventricular and supraoptic nuclei in suckled rats: direct proof with paired extracellular recordings. Exp Brain Res 57:201-203.

Bell AF, Erickson EN, Carter CS (2014) Beyond labor: the role of natural and synthetic oxytocin in the transition to motherhood. Journal of Midwifery and Womens Health 59:35-42.

Bitran D, Hull EM (1987) Pharmacological analysis of male rat sexual behavior. Neurosci Biobehav Rev 11:365-389.

Böckers TM, Mameza MG, Kreutz MR, Bockmann J, Weise C, Buck F, Richter D, Gundelfinger ED, Kreienkamp HJ (2001) Synaptic scaffolding proteins in rat brain. ankyrin repeats of the multidomain shank protein family interact with the cytoskeletal protein alpha-fodrin. J Biol Chem 276: 40104-40112.

Brimble MJ, Dyball RE, Forsling ML (1978) Oxytocin release following osmotic activation of oxytocin neurones in the paraventricular and supraoptic nuclei. J Physiol 278:69-78.

Brown CH, Brunton PJ, Russell JA (2008) Rapid estradiol-17 $\beta$ modulation of opioid actions on the electrical and secretory activity of rat oxytocin neurons in vivo. Neurochem Res 33:614-623.

Caquineau C, Leng G, Guan XM, Jiang M, Van der Ploeg L, Douglas AJ (2006) Effects of $\alpha$-melanocyte-stimulating hormone on magnocellular oxytocin neurones and their activation at intromission in male rats. J Neuroendocrinol 18:685-691.

Carter CS (2014) Oxytocin pathways and the evolution of human behavior. Annu Rev Psychol 65:17-39.

Chen TW, Wardill TJ, Sun Y, Pulver SR, Renninger SL, Baohan A, Schreiter ER, Kerr RA, Orger MB, Jayaraman V, Looger LL, Svoboda K, Kim DS (2013) Ultrasensitive fluorescent proteins for imaging neuronal activity. Nature 499:295-300.
Chevallier C, Kohls G, Troiani V, Brodkin ES, Schultz RT (2012) The social motivation theory of autism. Trends Cogn Sci 16:231-239.

Choe HK, Reed MD, Benavidez N, Montgomery D, Soares N, Yim YS, Choi GB (2015) Oxytocin mediates entrainment of sensory stimuli to social cues of opposing valence. Neuron 87:152-163.

Crawley JN (2008) Behavioral phenotyping strategies for mutant mice. Neuron 57:809-818.

Dölen G, Darvishzadeh A, Huang KW, Malenka RC (2013) Social reward requires coordinated activity of nucleus accumbens oxytocin and serotonin. Nature 501:179-184.

Donaldson ZR, Young LJ (2008) Oxytocin, vasopressin, and the neurogenetics of sociality. Science 322:900-904.

Ebner K, Wotjak CT, Landgraf R, Engelmann M (2000) A single social defeat experience selectively stimulates the release of oxytocin, but not vasopressin, within the septal brain area of male rats. Brain Res 872:87-92.

Ferguson JN, Aldag JM, Insel TR, Young LJ (2001) Oxytocin in the medial amygdala is essential for social recognition in the mouse. J Neurosci 21:8278-8285.

Gimpl G, Fahrenholz F (2001) The oxytocin receptor system: structure, function, and regulation. Physiol Rev 81:629-683.

Hammock EA (2015) Developmental perspectives on oxytocin and vasopressin. Neuropsychopharmacology 40:24-42.

Hicks C, Jorgensen W, Brown C, Fardell J, Koehbach J, Gruber CW, Kassiou M, Hunt GE, McGregor IS (2012) The nonpeptide oxytocin receptor agonist WAY 267,464: receptor-binding profile, prosocial effects and distribution of c-fos expression in adolescent rats. J Neuroendocrinol 24: 1012-1029.

Hung LW, Neuner S, Polepalli JS, Beier KT, Wright M, Walsh JJ, Lewis EM, Luo L, Deisseroth K, Dölen G, Malenka RC (2017) Gating of social reward by oxytocin in the ventral tegmental area. Science 357:1406-1411.

Insel TR (1992) Oxytocin-a neuropeptide for affiliation: evidence from behavioral, receptor autoradiographic, and comparative studies. Psychoneuroendocrinology 17:3-35.

Israel JM, Le Masson G, Theodosis DT, Poulain DA (2003) Glutamatergic input governs periodicity and synchronization of bursting activity in oxytocin neurons in hypothalamic organotypic cultures. Eur J Neurosci 17: $2619-2629$

Jaramillo TC, Speed HE, Xuan Z, Reimers JM, Escamilla CO, Weaver TP, Liu S, Filonova I, Powell CM (2017) Novel Shank3 mutant exhibits behaviors with face validity for autism and altered striatal and hippocampal function: Shank3 exon 13 mutant autism model. Autism Res 10:42-65.

Jiang YH, Ehlers MD (2013) Modeling autism by SHANK gene mutations in mice. Neuron 78:8-27.

Kaifosh P, Zaremba JD, Danielson NB, Losonczy A (2014) SIMA: Python software for analysis of dynamic fluorescence imaging data. Front Neuroinform 8:80.

Kanner L (1968) Autistic disturbances of affective contact. Acta Paedopsychiatr 35:100-136

Kelly AM, Goodson JL (2014) Social functions of individual vasopressinoxytocin cell groups in vertebrates: what do we really know? Front Neuroendocrinol 35:512-529.

Luckman SM, Dyball RE, Leng G (1994) Induction of c-fos expression in hypothalamic magnocellular neurons requires synaptic activation and not simply increased spike activity. J Neurosci 14:4825-4830.

Ludwig M, Leng G (2006) Dendritic peptide release and peptide-dependent behaviours. Nat Rev Neurosci 7:126-136.

Marina JF, Bauermeister JJ (1974) Socially facilitated extinction of a conditioned avoidance response. Bull Psychon Soc 3:161-163.

Marlin BJ, Mitre M, D'amour JA, Chao MV, Froemke RC (2015) Oxytocin enables maternal behaviour by balancing cortical inhibition. Nature 520: 499-504.

Martin MM, Liu Y, Wang Z (2012) Developmental exposure to a serotonin agonist produces subsequent behavioral and neurochemical changes in the adult male prairie vole. Physiol Behav 105:529-535.

McHenry JA, Otis JM, Rossi MA, Robinson JE, Kosyk O, Miller NW, McEllicgott ZA, Budygin EA, Rubinow DR, Stuber GD (2017) Hormonal gain control of a medial preoptic area social reward circuit. Nature Neuroscience 20:449-458.

McNamara IM, Borella AW, Bialowas LA, Whitaker-Azmitia PM (2008) Further studies in the developmental hyperserotonemia model (DHS) of autism: social, behavioral and peptide changes. Brain Res 1189:203-214. Mitre M, Marlin BJ, Schiavo JK, Morina E, Norden SE, Hackett TA, Aoki CJ, 
Chao MV, Froemke RC (2016) A distributed network for social cognition enriched for oxytocin receptors. J Neurosci 36:2517-2535.

Modi ME, Inoue K, Barrett CE, Kittelberger KA, Smith DG, Landgraf R, Young LJ (2015) Melanocortin receptor agonists facilitate oxytocindependent partner preference formation in the prairie vole. Neuropsychopharmacology 40:1856-1865.

Moos F, Fontanaud P, Mekaouche M, Brown D (2004) Oxytocin neurones are recruited into co-ordinated fluctuations of firing before bursting in the rat. Neuroscience 125:391-410.

Nardou R, Lewis EM, Rothhaas R, Xu R, Yang A, Boyden E, Dölen G (2019) Oxytocin-dependent reopening of a social reward learning critical period with MDMA. Nature 569:116-120.

Ne'eman R, Perach-Barzilay N, Fischer-Shofty M, Atias A, Shamay-Tsoory SG (2016) Intranasal administration of oxytocin increases human aggressive behavior. Horm Behav 80:125-131.

Neumann ID (2007) Stimuli and consequences of dendritic release of oxytocin within the brain. Biochem Soc Trans 35:1252-1257.

Neumann ID (2008) Brain oxytocin: a key regulator of emotional and social behaviours in both females and males. J Neuroendocrinol 20:858-865.

Oettl LL, Ravi N, Schneider M, Scheller MF, Schneider P, Mitre M, da Silva Gouveia M, Froemke RC, Chao MV, Young WS, Meyer-Lindenberg A, Grinevich V, Shusterman R, Kelsch W (2016) Oxytocin enhances social recognition by modulating cortical control of early olfactory processing. Neuron 90:609-621.

Okabe S, Nagasawa M, Kihara T, Kato M, Harada T, Koshida N, Mogi K, Kikusui T (2013) Pup odor and ultrasonic vocalizations synergistically stimulate maternal attention in mice. Behav Neurosci 127:432-438.

Olszewski PK, Ulrich C, Ling N, Allen K, Levine AS (2014) A nonpeptide oxytocin receptor agonist, WAY-267,464, alleviates novelty-induced hypophagia in mice: insights into changes in c-Fos immunoreactivity. Pharmacol Biochem Behav 124:367-372.

Otis JM, Namboodiri VM, Matan AM, Voets ES, Mohorn EP, Kosyk O, McHenry JA, Robinson JE, Resendez SL, Rossi MA, Stuber GD (2017) Prefrontal cortex output circuits guide reward seeking through divergent cue encoding. Nature 543:103-107.

Ozonoff S, Iosif AM, Baguio F, Cook IC, Hill MM, Hutman T, Rogers SJ, Rozga A, Sangha S, Sigman M, Steinfeld MB, Young GS (2010) A prospective study of the emergence of early behavioral signs of autism. J Am Acad Child Adolesc Psychiatry 49:256-266.e1-2.

Peça J, Feliciano C, Ting JT, Wang W, Wells MF, Venkatraman TN, Lascola CD, Fu Z, Feng G (2011) Shank3 mutant mice display autistic-like behaviours and striatal dysfunction. Nature 472:437-442.

Pedersen CA, Prange AJ Jr (1979) Induction of maternal behavior in virgin rats after intracerebroventricular administration of oxytocin. Proc Natl Acad Sci U S A 76:6661-6665.

Peixoto RT, Wang W, Croney DM, Kozorovitskiy Y, Sabatini BL (2016) Early hyperactivity and precocious maturation of corticostriatal circuits in Shank3B-/- mice. Nat Neurosci 19:716-724.

Peñagarikano O, Lázaro MT, Lu XH, Gordon A, Dong H, Lam HA, Peles E, Maidment NT, Murphy NP, Yang XW, Golshani P, Geschwind DH (2015) Exogenous and evoked oxytocin restores social behavior in the Cntnap2 mouse model of autism. Sci Transl Med 7:271ra8.

Poulain DA, Wakerley JB (1982) Electrophysiology of hypothalamic magnocellular neurones secreting oxytocin and vasopressin. Neuroscience 7:773-808.

Resendez SL, Stuber GD (2015) In vivo calcium imaging to illuminate neurocircuit activity dynamics underlying naturalistic behavior. Neuropsychopharmacology 40:238-239.
Resendez SL, Jennings JH, Ung RL, Namboodiri VM, Zhou ZC, Otis JM, Nomura H, McHenry JA, Kosyk O, Stuber GD (2016) Visualization of cortical, subcortical and deep brain neural circuit dynamics during naturalistic mammalian behavior with head-mounted microscopes and chronically implanted lenses. Nat Protoc 11:566-597.

Ring RH, Schechter LE, Leonard SK, Dwyer JM, Platt BJ, Graf R, Grauer S, Pulicicchio C, Resnick L, Rahman Z, Sukoff Rizzo SJ, Luo B, Beyer CE, Logue SF, Marquis KL, Hughes ZA, Rosenzweig-Lipson S (2010) Receptor and behavioral pharmacology of WAY-267464, a nonpeptide oxytocin receptor agonist. Neuropharmacology 58:69-77.

Rossoni E, Feng J, Tirozzi B, Brown D, Leng G, Moos F (2008) Emergent synchronous bursting of oxytocin neuronal network. PLoS Comput Biol 4:e1000123.

Sabatier N, Leng G (2006) Presynaptic actions of endocannabinoids mediate MSH-induced inhibition of oxytocin cells. Am J Physiol Regul Integr Comp Physiol 290:R577-R584.

Sabatier N, Caquineau C, Dayanithi G, Bull P, Douglas AJ, Guan XM, Jiang M, Van der Ploeg L, Leng G (2003) Alpha-melanocyte-stimulating hormone stimulates oxytocin release from the dendrites of hypothalamic neurons while inhibiting oxytocin release from their terminals in the neurohypophysis. J Neurosci 23:10351-10358.

Scott N, Prigge M, Yizhar O, Kimchi T (2015) A sexually dimorphic hypothalamic circuit controls maternal care and oxytocin secretion. Nature 525:519-522.

Shamay-Tsoory SG, Abu-Akel A (2016) The social salience hypothesis of oxytocin. Biol Psychiatry 79:194-202.

Silverman JL, Yang M, Lord C, Crawley JN (2010) Behavioural phenotyping assays for mouse models of autism. Nat Rev Neurosci 11:490-502.

Summerlee AJ (1981) Extracellular recordings from oxytocin neurones during the expulsive phase of birth in unanaesthetized rats. J Physiol 321:1-9.

Summerlee AJ, Lincoln DW (1981) Electrophysiological recordings from oxytocinergic neurones during suckling in the unanaesthetized lactating rat. J Endocrinol 90:255-265.

Tabbaa M, Paedae B, Liu Y, Wang Z (2016) Neuropeptide regulation of social attachment: the prairie vole model. Compr Physiol 7:81-104.

Della Torre SD, Benedusi V, Fontana R, Maggi A (2014) Energy metabolism and fertility-a balance preserved for female health. Nat Rev Endocrinol $10: 13-23$

Wang Z, Aragona BJ (2004) Neurochemical regulation of pair bonding in male prairie voles. Physiol Behav 83:319-328.

Wu Z, Xu Y, Zhu Y, Sutton AK, Zhao R, Lowell BB, Olson DP, Tong Q (2012) An obligate role of oxytocin neurons in diet induced energy expenditure. PLoS One 7:e45167.

Yanagimoto M, Honda K, Goto Y, Negoro H (1996) Afferents originating from the dorsal penile nerve excite oxytocin cells in the hypothalamic paraventricular nucleus of the rat. Brain Res 733:292-296.

Young KA, Liu Y, Gobrogge KL, Wang H, Wang Z (2014) Oxytocin reverses amphetamine-induced deficits in social bonding: evidence for an interaction with nucleus accumbens dopamine. J Neurosci 34:8499-8506.

Young LJ, Wang Z (2004) The neurobiology of pair bonding. Nat Neurosci 7:1048-1054.

Zhu X, Gleiberman AS, Rosenfeld MG (2007) Molecular physiology of pituitary development: signaling and transcriptional networks. Physiol Rev 87:933-963.

Zimmermann FF, Gaspary KV, Siebel AM, Bonan CD (2016) Oxytocin reversed MK-801-induced social interaction and aggression deficits in zebrafish. Behav Brain Res 311:368-374. 